\title{
Getting the balance right: Established and emerging therapies for major depressive disorders
}

This article was published in the following Dove Press journal:

Neuropsychiatric Disease and Treatment

2 July 2010

Number of times this article has been viewed

\section{Bojana Perović \\ Marija Jovanović \\ Branislava Miljković Sandra Vezmar}

Department of Pharmacokinetics, Faculty of Pharmacy, University of Belgrade, Serbia
Correspondence: Sandra Vezmar Department of Pharmacokinetics, Faculty of Pharmacy,Vojvode Stepe 450, I 1000 , Belgrade, Serbia Tel +38 I I | 395 I 375

Fax +38 III 3974349

Email svezmar@pharmacy.bg.ac.rs
Abstract: Major depressive disorder (MDD) is a common and serious illness of our times, associated with monoamine deficiency in the brain. Moreover, increased levels of cortisol, possibly caused by stress, may be related to depression. In the treatment of MDD, the use of older antidepressants such as monoamine oxidase inhibitors and tricyclic antidepressants is decreasing rapidly, mainly due to their adverse effect profiles. In contrast, the use of serotonin reuptake inhibitors and newer antidepressants, which have dual modes of action such as inhibition of the serotonin and noradrenaline or dopamine reuptake, is increasing. Novel antidepressants have additive modes of action such as agomelatine, a potent agonist of melatonin receptors. Drugs in development for treatment of MDD include triple reuptake inhibitors, dual-acting serotonin reuptake inhibitors and histamine antagonists, and many more. Newer antidepressants have similar efficacy and in general good tolerability profiles. Nevertheless, compliance with treatment for MDD is poor and may contribute to treatment failure. Despite the broad spectrum of available antidepressants, there are still at least $30 \%$ of depressive patients who do not benefit from treatment. Therefore, new approaches in drug development are necessary and, according to current research developments, the future of antidepressant treatment may be promising.

Keywords: major depressive disorders, monoamine deficiency, antidepressants, depression

\section{Introduction}

Major depressive disorder (MDD) is a common and serious illness with the potential of becoming the leading cause of disability worldwide. ${ }^{1}$ The lifetime prevalence rate is $16.2 \%$, and is expected to increase. ${ }^{2,3}$ In the elderly, prevalence is about $3 \%$ in the general population ${ }^{4}$ and $15 \%-25 \%$ among nursing home residents. ${ }^{5}$ These numbers may be even higher, because it is estimated that clinically significant depression goes untreated in $60 \%$ of the elderly. ${ }^{6}$ The average age of onset of MDD is the mid- $20 \mathrm{~s}^{3}$ The lifetime risk in women is twice the risk in men, and is increased during the reproductive years. ${ }^{3}$

The illness is described by a wide range of symptoms, such as disturbances in sleep, appetite, sexual desire, and constipation. It is also characterized by crying, sadness, and loss of the ability to experience pleasure in work or with friends. Depression is strongly associated with suicidal events, cognitive abnormalities, impaired memory function, and slowing of speech and action. ${ }^{7}$ Furthermore, patients with MDD often have painful physical symptoms. ${ }^{8}$ If symptoms which interfere considerably with activities of daily living and domestic relationships persist for more than two weeks, MDD should be considered. ${ }^{7}$ 


\section{Mechanisms of disease}

MDD is a complex disorder, probably influenced by genetic and environmental factors. Heritability of depression has been estimated to range from $30 \%$ to $40 \%{ }^{3}$ The polymorphisms associated with the serotonin transporter gene ${ }^{9}$ have been related to more depressive symptoms, diagnosable depression, and tendency to commit suicide. ${ }^{3,10}$ Nevertheless, the relationship between genetics and depression is probably very complex and not fully elucidated. ${ }^{7}$

Some environmental factors, such as stress, could predispose to depression by affecting the genome. ${ }^{7,9}$ Personality characteristics may predict an individual's susceptibility to depression, but personality may also be modified in the disease. Moreover, personality may alter the clinical presentation of a depressive disorder. ${ }^{11}$

\section{Monoamine deficiency hypothesis}

The monoamine hypothesis of depression postulates a deficiency in monoaminergic neurotransmission in the brain, mediated by serotonin and noradrenaline. Noradrenaline depletion may be due to inhibition of tyrosine hydroxylase (see Figure 1), whereas reduced synthesis of serotonin may be due to depletion of dietary tryptophan or mutations of tryptophan hydroxylase. ${ }^{7,12}$ Given that reduced serotonin levels do not cause depression in all people, it is unclear if decreased serotonin synthesis is a cause or consequence of depression. ${ }^{9}$

Deficiency in monoaminergic neurotransmission may be caused by disturbed receptor signaling, even with normal monoamine levels. Decreased sensitivity of $5-\mathrm{HT}_{1 \mathrm{~A}}$ and $5-\mathrm{HT}_{1 \mathrm{~B}}$ autoreceptors, which regulate serotonin function, has been associated with depression. ${ }^{13,14}$ In contrast, the sensitivity of $\alpha_{2}$-noradrenergic receptors, which modulate noradrenaline release by feedback inhibition, was enhanced in depressed patients. ${ }^{15}$ Moreover, disturbed receptor signaling could also be a result of malfunction of G-protein or secondary messenger systems, which may impair neurotransmitter function, even without changes in monoamine levels or receptor numbers. ${ }^{7}$ Decreased levels of secondary messengers, such as inositol, ${ }^{7,16} \mathrm{cAMP}^{7,17}$ and cAMP response element-binding protein, have been reported in the brains of patients with MDD at autopsy. ${ }^{7,18}$

The monoamine deficiency hypothesis is supported by the fact that noradrenaline and serotonin reuptake inhibitors have antidepressant activity. Nevertheless, only $50 \%-70 \%$ of patients respond to these drugs, implicating a more complex mechanism for depression. ${ }^{7,19}$ Furthermore, dopamine deficiency has been associated with the disease as well.
Such a hypothesis is supported by the antidepressant activity of dopamine reuptake inhibitors and dopamine agonists.

\section{Stress, hypothalamic-pituitary-adrenal axis, and growth factors}

Stress is perceived by the brain cortex and transmitted to the hypothalamus, where corticotrophin-releasing hormone is produced and released, leading to further elevation of cortisol plasma levels. The hypothalamic-pituitary-cortisol hypothesis postulates that depression is associated with elevated cortisol levels in response to stress. ${ }^{20,21}$ However, doubt was cast on this hypothesis by disappointing results in clinical trials with corticotrophin-releasing hormone antagonists. ${ }^{22}$ It is also difficult to establish the relationship between stress and depression, given that stress may be both the cause and consequence of depressed mood.?

It was suggested that elevated levels of glucocorticoids may reduce neurogenesis and lead to decreased size of the hippocampus in some depressed patients. ${ }^{23}$ Stress and cortisol may affect and decrease hippocampal levels of brain-derived neurotrophic factor, necessary for axonal growth, neuronal survival, and synaptic plasticity. ${ }^{24-26}$ Reduced brain-derived neurotrophic factor levels were found in the hippocampi of depressed patients. ${ }^{24}$

\section{Other possible disease mechanisms}

Other theories about the pathophysiology of depression include changes in glutamatergic neurotransmission, ${ }^{25}$ reduced neurotransmission gamma-butyric acid, ${ }^{26}$ abnormal circadian rhythms,${ }^{27}$ deficient neurosteroid synthesis,${ }^{28}$ impaired endogenous opioid function, ${ }^{29}$ monoamine-acetylcholine imbalance, ${ }^{30}$ tyroxine abnormalities, ${ }^{31}$ and dysfunction of specific brain structures and circuits. ${ }^{32}$ Many of these mechanisms are involved in other psychiatric and neurologic disorders, but the impact on MDD is still unclear.

\section{Traditional therapy}

The most common nonpharmacologic approach for treating MDD is psychotherapy. It is especially helpful in patients with a history of childhood adversity or recent stress. ${ }^{33}$ Psychotherapy and medication were shown to be comparable for unipolar depression, and it was suggested that psychotherapy may offer a prophylactic advantage compared with medication. ${ }^{34}$ Other possible approaches include neurostimulation techniques, electroshock, or electroconvulsive therapy, indicated only for treatment of resistant depression. ${ }^{9}$

Traditional pharmacotherapy includes tricyclic antidepressants (TCAs) and monoamine oxidase inhibitors (MAOIs). 


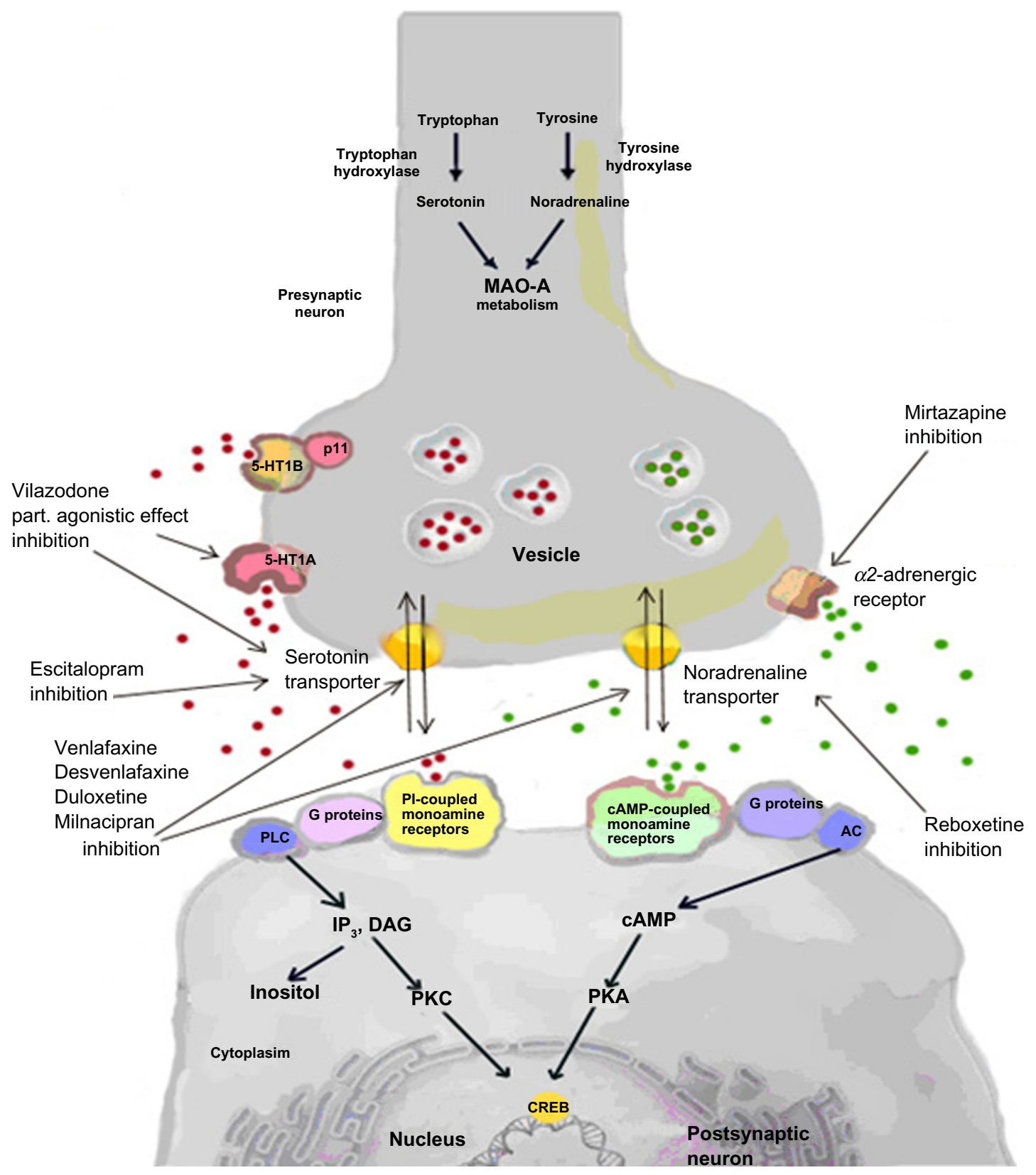

Figure I The monoamine deficiency hypothesis.

Abbreviations: MAO-A, monoamine oxidase A; PLC, phospholipase-C; AC, adenylate cyclase; IP, ionsitol trisphosphate; PKC, protein kinase c; DAG, diacylglycerol; cAMP, cyclic AMP; CREB, cAMP response element binding.

However, selective serotonin reuptake inhibitors (SSRIs) and newer antidepressants are considered as "first-line" treatment.

\section{Monoamine oxidase inhibitors}

MAOIs inhibit MAO-A and MAO-B and reduce monoamine degradation. Phenelzine, isocarboxazid and tranylcypromine are irreversible nonselective inhibitors, and their effect may persist for weeks until the regeneration of MAO. The use of MAOIs is decreasing due to serious side effects, such as acute hypertensive reactions after consumption of tyramine-rich foods, eg, aged cheese. ${ }^{35}$ These drugs have severe, potentially life-threatening interactions with many drugs, including meperidine, SSRIs, narcotic medications, and pseudoephedrine. ${ }^{36}$ Newer MAOIs inhibit the MAO enzyme reversibly. Moclobemide inhibits MAO-A, and does not require strict dietary restrictions. ${ }^{39}$ Selegiline inhibits MAO-B, and its transdermal formulation provides several advantages compared with orally administered MAOIs, including freedom from dietary tyramine restrictions and a better adverse effect profile. ${ }^{37}$ 


\section{Tricyclic antidepressants}

The mechanism of action of most TCAs is noradrenaline and serotonin reuptake inhibition. ${ }^{38}$ They also antagonize post-synaptic histamine $\mathrm{H}_{1}, \alpha_{1}, 5 \mathrm{HT}_{2 \mathrm{~A}}$, and muscarinic receptors. ${ }^{41}$ Following oral administration, TCAs are rapidly absorbed. They are highly (90\%-95\%) bound to plasma albumin, and have large distribution volumes. ${ }^{41}$ Metabolism occurs primarily by CYP450 (CYP2D6, CYP2C9, CYP2C19, and CYP3A4), and metabolites are renally excreted. ${ }^{41}$ TCAs may interact with SSRIs by inhibition of CYP450 isoenzymes. Concurrent use of fluoxetine or paroxetine can enhance TCA concentrations. ${ }^{41}$ Concurrent use of imipramine and clomipramine with MAOIs may cause pharmacodynamic interactions leading to serotonin syndrome. ${ }^{41}$ Although widely used in clinical practice, combinations of TCAs with MAOIs and SSRIs are generally considered to be unsafe. ${ }^{41}$ TCAs have a small therapeutic range, and therapeutic drug monitoring is useful. ${ }^{39}$ Female gender and higher drug doses increase the risk of side effects. ${ }^{40}$

TCAs were shown to be comparable or more effective than SSRIs, but less well tolerated. ${ }^{41}$ Their advantage may be efficacy in treatment-resistant depression.$^{42}$ Nortriptyline, a potent noradrenaline reuptake inhibitor showed superior pharmacologic properties compared with other TCAs. ${ }^{41}$ Nortriptyline was better tolerated and may be administered concomitantly with MAOIs or SSRIs ${ }^{41}$ Clomipramine may be the most efficacious TCA in severe depression. ${ }^{41}$ Amitriptyline is considered very effective, whereas dothiepin has the highest toxicity among the TCAs. ${ }^{41}$ The more typical atropinic side effects of TCAs ${ }^{41}$ are presented in Table 1. Enhanced and toxic concentrations of TCA cause serious adverse effects, such as prolonged intracardiac conduction and postural hypotension. ${ }^{41,43}$

\section{Selective serotonin reuptake inhibitors}

SSRIs selectively inhibit neuronal reuptake of serotonin, with no significant affinity for histamine, acetylcholine, or adrenergic receptors. The most frequently used SSRIs in the treatment of depression are fluoxetine, fluvoxamine, sertraline, paroxetine, citalopram, and escitalopram. ${ }^{43}$ These agents have similar efficacy and tolerability. ${ }^{44}$ However, due to pharmacokinetic differences, they are not interchangeable. ${ }^{45}$ Sertraline and citalopram show linear pharmacokinetics in contrast with fluoxetine, fluvoxamine, and paroxetine. SSRIs are usually characterized by slow elimination, and it takes time to achieve steady state. ${ }^{47}$ Fluoxetine has a half-life of 1-4 days and its active metabolite norfluoxetine 7-15 days. Other SSRIs have shorter half-lives of 1-2 days and no clinically significant active metabolites. ${ }^{47}$ SSRIs are extensively metabolized and show high interindividual variability. ${ }^{47}$ Fluoxetine and norfluoxetine are inhibitors of CYP2D6 ${ }^{46,47}$ and CYP3A4. ${ }^{46}$ Paroxetine inhibits CYP2D6, ${ }^{47-49}$ while fluvoxamine inhibits CYP1A2 and CYP2C19. ${ }^{48,49}$ As a consequence, their potential to interact with antipsychotics, opioids, and serotonin-norepinephrine reuptake inhibitors is high. ${ }^{48}$ Clinically significant interactions are more likely to occur with fluvoxamine, fluoxetine, and paroxetine compared with citalopram, escitalopram, or sertraline. ${ }^{48}$

Drug interactions with MAOIs, TCAs, moclobemide, tryptophan, lithium, and selegiline, as well as SSRI overdoses, may lead to the serotonin syndrome, characterized by change in mental status, myoclonus, restlessness, hyperreflexia, shivering, diaphoresis, tremor, and possibly death. ${ }^{47,48}$ SSRIs cause fewer side effects, such as dry mouth, constipation, and blurred vision, and have a safer cardiac adverse event profile than the TCAs. ${ }^{47,48}$ Common adverse effects of SSRIs are listed in Table 1.

Paroxetine is a more potent noradrenaline inhibitor compared with the other SSRIs and has the highest affinity for cholinergic receptors causing typical anticholinergic adverse effects. ${ }^{48}$ Sertraline significantly blocks dopamine reuptake, which may result in cardiovascular and extrapyramidal symptoms. ${ }^{48}$ Fluoxetine and sertraline have high dopaminergic affinity that may also cause extrapyramidal symptoms. Citalopram has the highest affinity for $\mathrm{H}_{1}$ receptors of all the SSRIs, and may have weak antihistaminic activity at high doses. ${ }^{47,48}$ Despite these adverse effects, SSRIs remain reasonably well tolerated. ${ }^{44,48}$

\section{Newer antidepressants}

Newer antidepressants are usually characterized by a dual mode of action, such as inhibition of serotonin, noradrenaline, and dopamine reuptake. The pharmacokinetics, efficacy, and adverse effects of the newer antidepressants will be discussed in detail.

\section{Escitalopram}

Escitalopram is the most 5-HT transporter-selective compound and the $\mathrm{S}-(+)$-enantiomer of citalopram. ${ }^{47}$ Both SSRIs share similar pharmacokinetics. ${ }^{22}$ Following oral administration, escitalopram is rapidly and almost completely absorbed. ${ }^{48,49}$ The process is not affected by food. ${ }^{55}$ The pharmacokinetic profiles of the newer antidepressants are summarized in Table 2. Escitalopram is widely distributed throughout tissues, ${ }^{55,56}$ has low protein binding, and is not likely to have interactions with highly protein-bound drugs. ${ }^{55}$ 
Table I Efficacy and adverse effects of triciclyc antidepressants, serotonin reuptake inhibitors and newer antidepressants

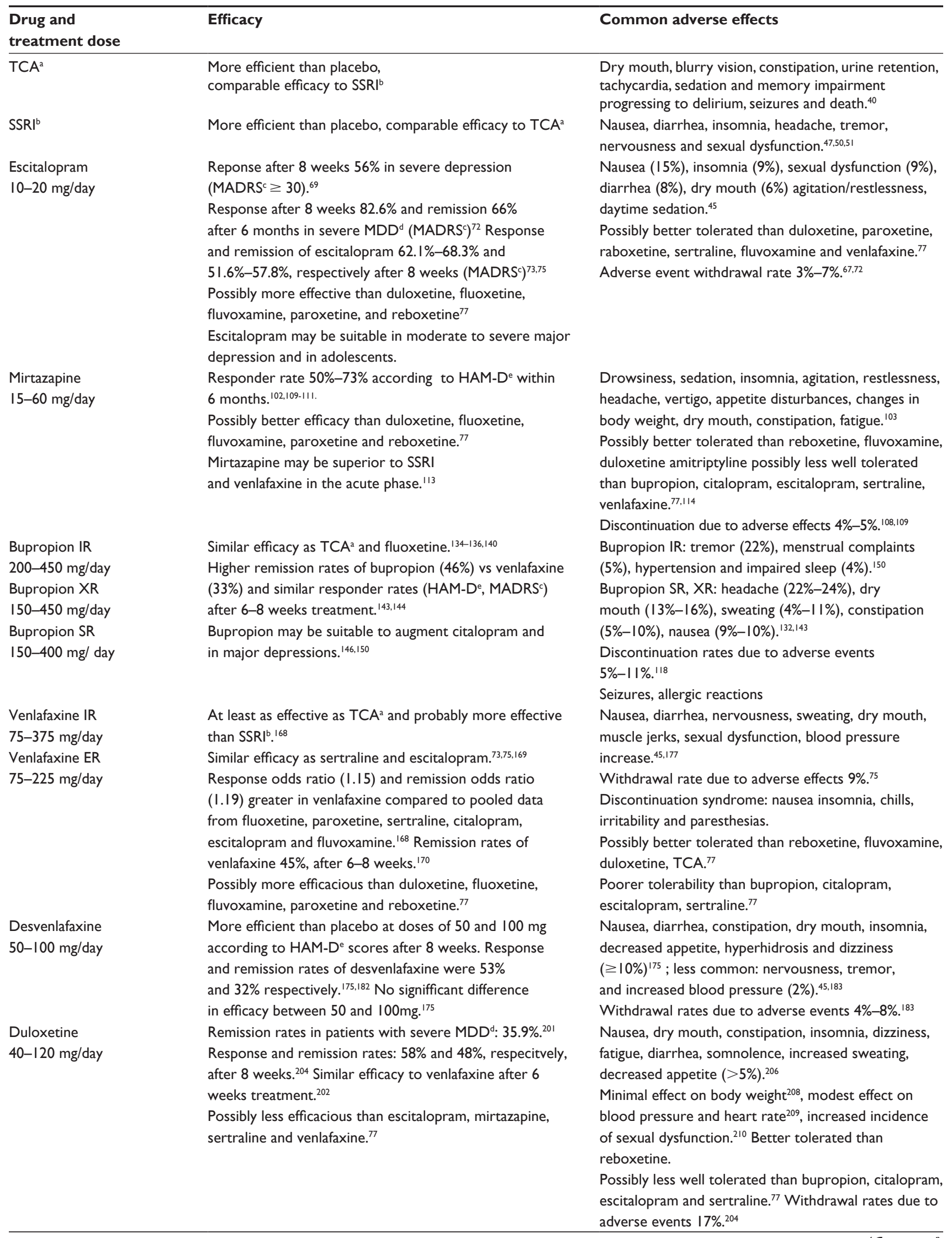


Table I (Continued)

\begin{tabular}{|c|c|c|}
\hline $\begin{array}{l}\text { Drug and } \\
\text { treatment dose }\end{array}$ & Efficacy & Common adverse effects \\
\hline $\begin{array}{l}\text { Milnacipran } \\
100-200 \mathrm{mg} / \text { day }\end{array}$ & $\begin{array}{l}\text { Reponse to treatment after } 8 \text { weeks } 65 \% \text { at dose } \\
50 \text { mg/day (HDRS). }{ }^{222} \text { Response rate } 58.9 \% \text { MADRSc } \\
\text { and } 59.7 \% \text { HAM-D }{ }^{2}{ }^{222,224} \\
\text { Possibly less efficacious than mirtazapine, escitalopram, } \\
\text { venlafaxine, sertraline and citalopram. Possibly more } \\
\text { efficacious than bupropion, duloxetine, fluvoxamine, } \\
\text { paroxetine, fluoxetine and reboxetine. }{ }^{77}\end{array}$ & $\begin{array}{l}\text { Nausea, nervousness, constipation, vertigo ( } 5 \%) \text {, } \\
\text { anxiety ( } 4 \%) \text {, hot flushes ( } 3 \%) \text {, dysuria ( } 2 \%) \text {, dizziness, } \\
\text { sweating ( } 4 \%)^{45,226} \\
\text { Possibly better tolerated than TCA, reboxetine, } \\
\text { fluvoxamine, fluoxetine, mirtazapine, venlafaxine, } \\
\text { duloxetine, paroxetine. }{ }^{77,225} \text { and possibly less well } \\
\text { tolerated than bupropion, citalopram, escitalopram, }_{\text {sertraline. }}^{77}\end{array}$ \\
\hline $\begin{array}{l}\text { Reboxetine } \\
4-10 \mathrm{mg} / \text { day }\end{array}$ & 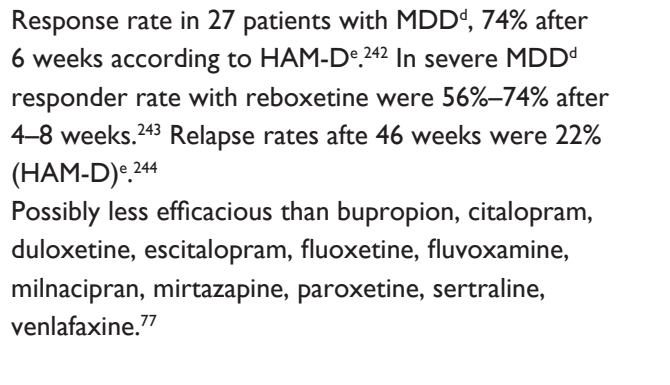 & $\begin{array}{l}\text { Dry mouth, insomnia, headache, constipation, } \\
\text { sweating, nausea, dizziness, anorexia and asthenia } \\
(>5 \%) .^{240} \\
\text { Male patients: tachycardia, urinary retention or } \\
\text { hesitancy, impotence and sexual dysfunction. }{ }^{240} \\
\text { Frequency of discontinuation was } 10 \%{ }^{245} \\
\text { Possibly less well tolerated than bupropion, citalopram, } \\
\text { duloxetine, escitalopram, fluoxetine, fluvoxamine, } \\
\text { milnacipran, mirtazapine, paroxetine, sertraline, } \\
\text { venlafaxine. }{ }^{77}\end{array}$ \\
\hline $\begin{array}{l}\text { Agomelatine } \\
25-50 \mathrm{mg} / \text { day }\end{array}$ & $\begin{array}{l}\text { Response to treatment was } 56 \%-63 \% \text { and remission } 30 \% \\
\left.\text { after } 8 \text { weeks (HAM-D } .{ }^{255} \text { Response rate } 49 \% \text { (HAM-D }\right) \\
\text { and improvement in CGI-Sf after } 6 \text { weeks was reported, } \\
\text { remission rate } 21 \% .{ }^{254}\end{array}$ & $\begin{array}{l}\text { Nausea dizzines ( } 9 \%) \text {, dry mouth, diarrhea } \\
\text { nasopharyngitis (7\%) and influenza (7\%). }{ }^{250,254} \\
\text { absence of serotonin syndrome, weight gain and low } \\
\text { incidence of sexual dysfunction and gastrointestinal } \\
\text { side effects. }^{250}\end{array}$ \\
\hline $\begin{array}{l}\text { Aripiprazole } \\
2-5 \mathrm{mg} / \text { day }\end{array}$ & $\begin{array}{l}\text { Remission rates with adjunctive aripiprazole to standard } \\
\text { antidepressant treatment vs placebo } 25.4 \% \text { vs } 15.2 \% \text {, } \\
\text { response rates } 32.4 \% \text { vs } 17.4 \% \text { respectively after } 6 \\
\text { weeks. }^{262} \text { Mean change in MADRS } \text { total score was }^{\text {ch }} \text { significantly greater with adjunctive aripiprazole }-8.8 \text { than } \\
\text { adjunctive placebo }-5.8 \text { after } 6 \text { weeks. }{ }^{261}\end{array}$ & $\begin{array}{l}\text { Akhatisia }(23 \%) \text {, nausea }(3 \%) \text {, insomnia }(8 \%) \text {, } \\
\text { restlessness ( } 14 \%) \text {, upper respiratory tract infections } \\
(8 \%) \text {, weight gain. }{ }^{261,262}\end{array}$ \\
\hline
\end{tabular}

Abbreviations: TCA, tricyclic antidepressants; SSRI, selective serotonin reuptake inhibitors; MADRS, Montgomery Asberg Depression Rating Scale; MDD, major depressive disorder; HAM-D, Hamilton Rating Scale for Depression; CGI-S, Clinical Global Impressions-Severity of illness scale.

Escitalopram is extensively metabolized in the liver via oxidative metabolism. ${ }^{50,55}$ In the brain, metabolism of escitalopram propionate may be mediated by MAO-A, MAO-B, and aldehyde oxidase. ${ }^{51,52}$ Nevertheless, the metabolites do not contribute appreciably to therapeutic activity.

Escitalopram is a weak inhibitor of CYP isoenzymes 1A2, 2C9, 2D6, and 3A4, and may have a low potential for clinically significant interactions with substrates for these isoenzymes. ${ }^{55}$ Ritonavir, a potent CYP3A4 inhibitor, showed no effect on escitalopram pharmacokinetics. ${ }^{53}$ In contrast, cimetidine and omeprazole increased escitalopram exposure, but the effect is probably not of clinical concern. ${ }^{54}$ Concomitant administration of escitalopram with MAOIs or other SSRIs should be avoided because of possible serotonin syndrome. ${ }^{55}$

The elimination half-life is relatively short compared with other SSRIs, and steady-state plasma concentrations are achieved in a week. ${ }^{56}$ The main elimination route is renal. ${ }^{55}$

Escitalopram shows linear and dose-proportional pharmacokinetics in the dose range $10-30 \mathrm{mg} /$ day. ${ }^{55,56}$ No reduction of citalopram dosage seems to be necessary in patients with moderately impaired renal function, but may be appropriate in patients with impaired hepatic function. ${ }^{55}$ Age and gender showed no clinically significant influence on escitalopram pharmacokinetics. ${ }^{55,56}$ Risk factors which may necessitate dose adjustment are presented in Table 3.

Escitalopram may be a suitable first-line antidepressant in moderate to severe major depression ${ }^{57}$ and in treatment of depression in adolescents. ${ }^{58}$ The drug was shown to be more efficacious than placebo and as least as effective or better than citalopram, ${ }^{22,66-69}$ with an early onset of efficacy. ${ }^{22,59}$ Differences between the two SSRIs seem to depend on the initial severity of the depressive symptomatology, given that escitalopram has shown superior antidepressive efficacy in severely depressed patients. ${ }^{60,70}$ Nevertheless, opposite findings were also reported, suggesting methodologic flaws as a cause for the difference in efficacy between the two drugs. ${ }^{60}$ Efficacy scores for newer antidepressants are presented in Table 1.

Escitalopram showed similar efficacy to sertraline ${ }^{61}$ and superior efficacy to paroxetine, especially in severely 


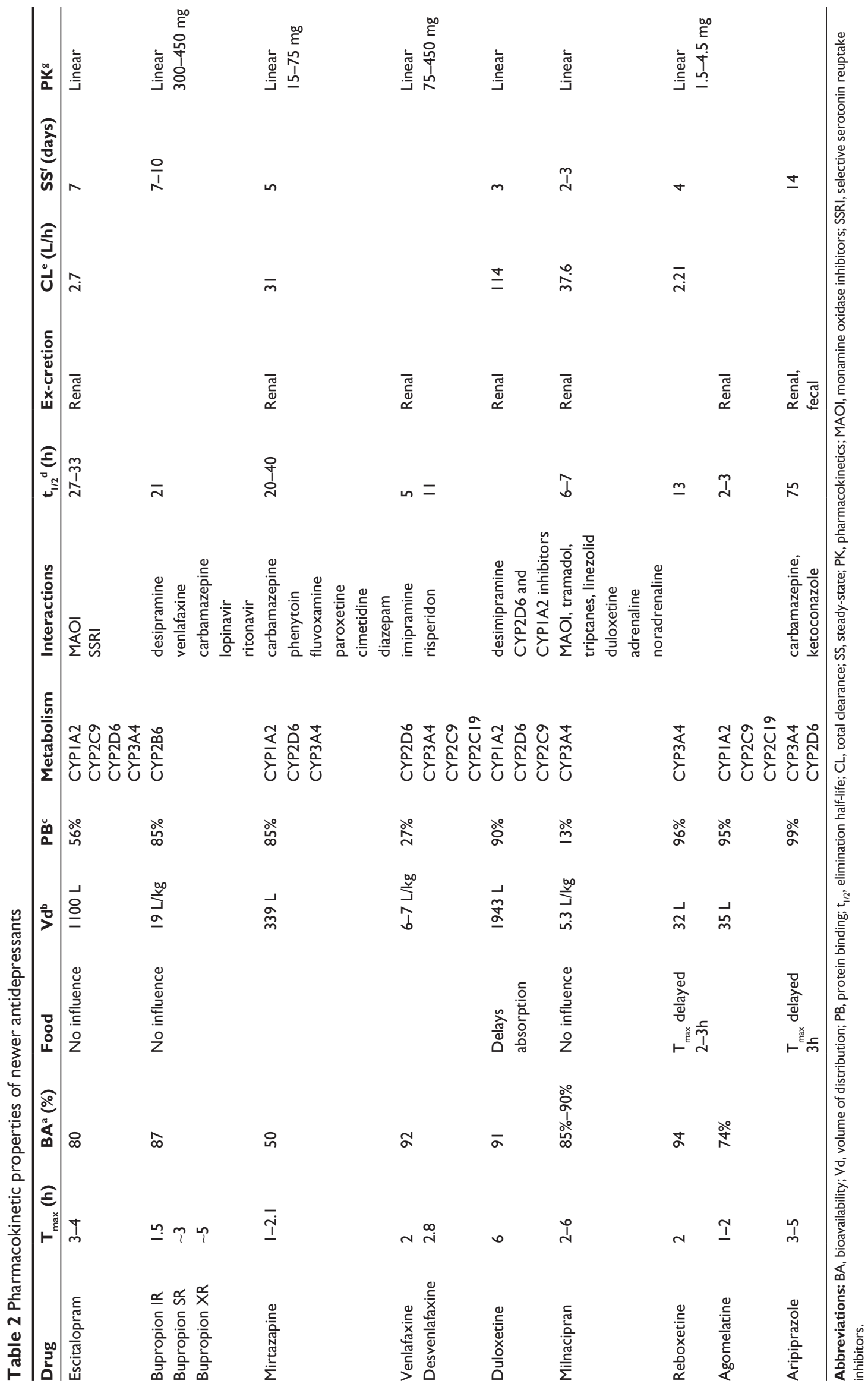


Table 3 Risk factors which may influence the pharmacokinetics of newer antidepressants

\begin{tabular}{ll}
\hline Drug & Factors that may require dose adjustment \\
\hline Escitalopram & Dose adjustment recommended in patients with impaired hepatic function \\
Mirtazapine & Age (elderly), hepatic impairment, caution in patients with moderate or severe renal insuficiency \\
Bupropion & Gender; caution in elderly, and those with renal and hepatic impairment. \\
Venlafaxine/Desvenlafaxine & Renal and hepatic impairment \\
& If creatinine clearance is $\leq 30 \mathrm{~mL} /$ min dose adjustment for venlafaxine recommended \\
Duloxetine & Hepatic impairment, neccessary dose adjustment. \\
Milnacipran & Gender, age, nicotine and race - monitor adverse effects, dose adjustment if necessary \\
Reboxetine & Caution in severe hepatic and moderate to severe renal impairment \\
Agomelatine & Elderly require lower starting doses \\
& Caution in renal and hepatic dysfunction \\
& Caution in patients with hepatic impairment; lack of data about other effects
\end{tabular}

depressed patients. ${ }^{62}$ Furthermore, in short-term studies, superior efficacy of escitalopram compared with citalopram, paroxetine, and duloxetine was observed. ${ }^{63}$

The efficacy of escitalopram was similar to that of venlafaxine, but there was a trend of higher response and remission rates in the escitalopram group. ${ }^{64,65}$ The SSRI may be at least as effective as venlafaxine and duloxetine even in severe depression. ${ }^{66}$

Cipriani et al reported superior efficacy of escitalopram over duloxetine, fluoxetine, fluvoxamine, paroxetine, and reboxetine. Following mirtazapine, escitalopram was the most efficacious drug among 12 antidepressants. ${ }^{67}$

The prominent side effects of escitalopram are similar to those of other SSRIs (see Table 2). ${ }^{46}$ Similar tolerability and withdrawal rates for citalopram and escitalopram were reported..$^{22,67-69}$ In contrast, escitalopram (10-20 mg/day) showed better tolerability in long-term treatment than paroxetine. The most common adverse event with escitalopram was headache, and nausea with paroxetine. ${ }^{74}$ Moreover, nausea, sweating, and obstipation were significantly less frequent compared with venlafaxine. ${ }^{22,68}$ Cipriani et al reported better tolerability of escitalopram compared with duloxetine, paroxetine, reboxetine, sertraline, fluvoxamine, and venlafaxine. ${ }^{79}$

Doses of 10-20 mg/day showed consistent antidepressive efficacy and excellent tolerability in primary care patients with MDD. ${ }^{68}$ The recommended starting dose of $10 \mathrm{mg} /$ day is appropriate for most patients regardless of age, gender, or mild to moderate renal impairment or hepatic insufficiency. ${ }^{55}$ A period of at least four weeks is worthwhile before considering further intervention. If $10 \mathrm{mg} /$ day is not effective, an increase to $20 \mathrm{mg}$ /day should be considered. ${ }^{69,70}$

\section{Mirtazapine}

The antidepressant activity of mirtazapine is a result of enhanced serotonergic and noradrenergic neurotransmission through blockade of presynaptic $\alpha_{2}$-adrenergic autoreceptors and heteroreceptors and postsynaptic $5-\mathrm{HT}_{2}$ and $5-\mathrm{HT}_{3}$ receptors. ${ }^{71,72}$ No influence on serotonin or noradrenaline reuptake was observed. ${ }^{73,84}$ Mirtazapine has low affinity for central and peripheral dopaminergic and muscarinic receptors, and high affinity for $\mathrm{H}_{1}$ receptors. ${ }^{83,84}$

Following oral administration, mirtazapine is rapidly absorbed, but the absolute bioavailability is moderate (see Table 2). ${ }^{73}$ The drug is nonspecifically and reversibly bound to proteins and possess a high distribution volume..$^{75,86}$ Metabolism is mediated by CYP1A2, CYP2D6, and CYP3A4. ${ }^{75,87}$ Demethylmirtazapine is the active metabolite, but its exposure in the human body is three times lower compared with the parent drug. ${ }^{74}$

Low inhibitory effects of mirtazapine on major CYP isoenzymes were reported in vitro. ${ }^{83,88}$ No significant interactions with the CYP2D6 substrates amitriptyline, clozapine, olanzapine, and risperidone were observed..$^{90-92}$ In contrast, plasma concentrations of mirtazapine were reduced after concomitant administration of the CYP3A4 inducers carbamazepine ${ }^{87,90}$ and phenytoin. ${ }^{75}$ Moreover, mirtazapine disposition was affected by fluvoxamine and, to a lesser extent, by paroxetine. ${ }^{76,77}$ Coadministration of cimetidine (an inhibitor of CYP3A4, CYP1A2, and CYP2D6) increased mirtazapine plasma concentrations significantly, requiring dose adjustment. ${ }^{78}$ An additive sedative effect was observed with diazepam. Moreover, patients should be advised to avoid alcohol while taking mirtazapine..$^{83,87}$

The drug is predominantly excreted in the urine and feces. ${ }^{87,89}$ The activity is prolonged by the circulation of the parent compound ${ }^{87,89}$ High clearance values indicate renal tubular secretion..$^{83,87,89}$ The elimination rate is strongly affected by CYP2D6 polymorphism. ${ }^{79,80}$ Steady state is reached in less than a week. ${ }^{81}$

In the therapeutic range, mirtazapine shows linear pharmacokinetics. ${ }^{99}$ Nicotine may decrease plasma mirtazapine 
levels, and smokers may require increased doses. ${ }^{82}$ In contrast, mirtazapine plasma levels are increased in the elderly, ${ }^{91,100}$ as well as in patients with hepatic impairment, ${ }^{87}$ and dose reduction should be considered in both groups. Mirtazapine exposure in patients with severe or moderate renal insufficiency is increased compared with healthy controls. ${ }^{83}$ Although there are no differences in reported adverse effects, ${ }^{102}$ the drug should be used with caution in these patients. ${ }^{84}$ Gender affects mirtazapine plasma levels, but the changes are not clinically important (see Table 3 ). ${ }^{101}$

The efficacy of mirtazapine in treatment of patients with moderate to severe MDD was reported in several studies. ${ }^{104-106}$ Short-term studies revealed similar efficacy for mirtazapine and amitriptyline. ${ }^{107-109}$ Moreover, mirtazapine had a longer time to relapse than amitriptyline during the first 20 weeks (see Table 1). ${ }^{85}$

Furthermore, mirtazapine showed similar or greater efficacy than citalopram, fluoxetine, paroxetine, sertraline, duloxetine, fluvoxamine, and reboxetine. ${ }^{79,111-114}$ In a meta-analysis of 25 randomized, controlled trials, mirtazapine showed a faster onset of action than SSRIs and was superior for short-term (two-week) response and remission rates, but the differences were not significant at the end of acute-phase treatment (6-12 weeks). ${ }^{86}$ The efficacy of mirtazapine and venlafaxine were similar in patients with severe depression characterized by melancholic features. ${ }^{87}$

Mirtazapine was generally well tolerated in patients with MDD, with a lower frequency of side effects compared with placebo (see Table 1). ${ }^{84,96,105}$ Sedation, especially at low dose, and weight increase may be due to $\mathrm{H}_{1}$-receptor blockade. ${ }^{105} \mathrm{In}$ a long-term treatment study, weight gain was the only more frequent side effect with mirtazapine than placebo, whereas blood pressure and heart rate were similar. ${ }^{83,110,117}$

Compared with amitriptyline, mirtazapine had fewer adverse events and less need for discontinuation of treatment due to an adverse event. ${ }^{83,110}$ Dry mouth, vertigo, and weight increase were as frequent as with TCAs, but seizures were less frequent. ${ }^{22,84}$

Discontinuation rates due to adverse events for mirtazapine and SSRIs were similar. Mirtazapine was associated with significantly less insomnia, sexual dysfunction, and nausea than SSRIs, but with significantly more weight gain, dry mouth, fatigue, and excessive somnolence. ${ }^{88}$ Adverse effects such as increased salivation and weight gain were more frequent with mirtazapine compared with venlafaxine but sweating, constipation, increased sexual desire, and weight loss were more common with venlafaxine. ${ }^{116}$
Mirtazapine is used as a single agent, or in combination with SSRIs or venlafaxine. The recommended dose is $15-45 \mathrm{mg} /$ day, and it is generally given as a single dose in the evening. ${ }^{46}$

\section{Bupropion}

Bupropion is an atypical antidepressant, probably a selective inhibitor of noradrenaline and dopamine reuptake. Bupropion and its metabolites are slightly more potent inhibitors of dopamine than of noradrenaline reuptake, and do not affect the release or transport of other neurotransmitters, or have appreciable affinity for postsynaptic receptors including histamine, $\alpha$-adrenergic, serotonin, dopamine, or acetylcholine receptors. ${ }^{89,90}$

Bupropion is available in three oral formulations, ie, immediate-release (IR), sustained-release (SR), and extended-release (XR).${ }^{91}$ Absorption rates vary between the formulations, but there is no significant difference in the extent of absorption. ${ }^{120}$ Food does not affect absorption, which is at least $87 \%$ of an administered dose. ${ }^{120}$ Pharmacokinetics are linear in the therapeutic range (see Table 2). ${ }^{120,121}$

Bupropion is extensively distributed and bound to plasma proteins. ${ }^{121}$ Following hepatic metabolism via CYP2B6, three active metabolites, ie, hydroxybupropion, threohydrobupropion, and erythrohydrobupropion are formed. ${ }^{92,93}$ Hydroxybupropion and threohydrobupropion possess about $50 \%$ of the activity of the parent $\operatorname{drug}^{123}$ and their plasma concentrations are 4-7-fold and $\sim 5$-fold higher than bupropion, respectively.

Major effects of CYP2B6 genetic polymorphisms on the pharmacokinetics of bupropion have not been shown. ${ }^{94}$ However, concomitant administration of CYP2B6 inducers, such as carbamazepine, lopinavir, and ritonavir, decreased bupropion plasma levels..$^{90,95,96}$

Bupropion and hydroxybupropion may have a low potency for inhibition of CYP2D6. ${ }^{123}$ Coadministration of bupropion with the CYP2D6 substrates desipramine and venlafaxine resulted in increased levels of the substrates. ${ }^{90,97}$ A case of severe bradycardia was related to the addition of bupropion to metoprolol. ${ }^{98}$ Therefore, low doses should be used, and dose monitoring should be considered following concomitant administration of bupropion and CYP2D6 substrates with a narrow therapeutic range. ${ }^{90}$

The activity of bupropion is prolonged as a result of slow elimination of metabolites. ${ }^{121}$ Steady-state concentrations are reached after $7-10$ days. ${ }^{121}$ Renal excretion is predominant, but the drug and its active metabolites cross the blood-brain barrier and placenta, and are also excreted in human breast milk. ${ }^{120}$ 
The pharmacokinetic properties of bupropion are probably not influenced by nicotine. ${ }^{99,100}$ However, the effect of gender is unclear due to controversial findings. ${ }^{129-131}$ Bupropion SR is metabolized more rapidly in children compared with adults, ${ }^{121}$ and the elderly are at risk of accumulation of the drug and its metabolites. ${ }^{101}$ Slower elimination of bupropion was observed in patients with renal impairment, ${ }^{102}$ and high variability in pharmacokinetic parameters was observed in patients with hepatic impairment. Therefore, bupropion should be used with caution in these groups (see Table 3). ${ }^{121}$

Bupropion was shown to be more efficacious than placebo. Improvement in primary and secondary outcomes were observed after 6-8 weeks with all bupropion formulations in adults with moderate to severe depression. ${ }^{103,104,120}$

Bupropion IR showed similar efficacy to nortriptyline, ${ }^{105}$ amitriptyline, ${ }^{106}$ and fluoxetine. ${ }^{107}$ No significant differences in efficacy were observed with bupropion SR and sertraline after 8-16 weeks ${ }^{139-141}$ or fluoxetine. ${ }^{108}$ In the elderly, bupropion SR and paroxetine showed similar efficacy. ${ }^{109}$ There were no significant differences between bupropion XR and escitalopram ${ }^{110}$ or venlafaxine $\mathrm{XR}^{111,112}$ in terms of primary or secondary outcome measures. After switching from citalopram, bupropion SR was as effective as sertraline and venlafaxine XR. ${ }^{113}$ The drug was as effective as buspirone in augmentation of citalopram (see Table 1). ${ }^{114}$

Different formulations of bupropion have similar tolerability profiles and are generally well tolerated in adults and the elderly. ${ }^{120}$ Most adverse events associated with bupropion are mild to moderate in severity (see Table 1). ${ }^{120,134,135}$

Allergic reactions to bupropion occur rarely but, if symptoms arise, drug discontinuation should be advised. ${ }^{115,120}$ The risk of seizures is dose- but not formulation-dependent. ${ }^{120}$ Rate of seizures was $0.1 \%$ for doses of $100-300 \mathrm{mg} /$ day, and increased to $0.4 \%$ at doses of $300-450 \mathrm{mg} /$ day. ${ }^{120,125,149}$ Adverse events resulting in discontinuation of therapy were agitation, headache, nausea, and rash, which occurred at a rate of approximately $5 \%-11 \%$ with all bupropion products. ${ }^{149}$

Compared with nortriptyline, bupropion was associated with significantly fewer adverse events such as dry mouth, somnolence, and tachycardia. ${ }^{136}$ Generally, the tolerability profiles of bupropion and SSRIs are similar, although bupropion is associated with more headache and dry mouth. ${ }^{115,120}$ However, sexual dysfunction following SSRIs is not a problem with bupropion, ${ }^{151}$ and lower rates of somnolence and diarrhea are associated with this agent. ${ }^{151}$ Similar incidences of adverse events were reported for bupropion and venlafaxine. ${ }^{145}$

The administration of bupropion has certain advantages, such as a greater reduction in severity of symptoms and fewer adverse events. ${ }^{148}$ Bupropion is indicated in the treatment of adult patients with major depression but is not approved for use in pediatric patients. ${ }^{149}$ The recommended initial doses are $100 \mathrm{mg}$ of bupropion IR twice daily, $150 \mathrm{mg}$ of bupropion SR once daily, and $150 \mathrm{mg}$ of bupropion XR once daily. ${ }^{115,120}$ The maximum recommended dose is $450 \mathrm{mg}$ /day for IR (150 mg three times daily) and XR (450 mg in the morning) formulations, or 400 $\mathrm{mg}$ /day of bupropion SR (200 mg twice daily). ${ }^{120,152}$

\section{Venlafaxine and desvenlafaxine}

Venlafaxine probably inhibits serotonin uptake only in low doses, whereas both serotonin and noradrenaline uptake are inhibited following high doses. ${ }^{115}$ The drug does not possess significant affinity for $5 \mathrm{HT}_{1 \mathrm{~A}}, 5 \mathrm{HT}_{2 \mathrm{~A}}, \mathrm{D}_{2}$, muscarinic, or $\alpha_{1}$ - or $\alpha_{2}$-receptors, and does not inhibit MAO. ${ }^{116,153}$ Desvenlafaxine (O-desmethylvenlafaxine), the major metabolite of venlafaxine, has similar potency for the inhibition of serotonin and noradrenaline uptake. ${ }^{153}$

Following oral administration of venlafaxine, absorption starts after approximately 20 minutes and is completed within three hours for venlafaxine IR and for desvenlafaxine. ${ }^{116,117}$ Venlafaxine XR is absorbed more slowly, but the extent of absorption is similar between formulations. ${ }^{156}$

The drug is widely distributed in the body, with low protein binding and a high volume of distribution (see Table 2). ${ }^{118,119}$ Following oral absorption, venlafaxine undergoes extensive first-pass hepatic metabolism, where conversion to the active metabolite, desvenlafaxine, occurs via demethylation. ${ }^{157}$ This reaction is mediated by CYP2D6. ${ }^{120}$ Desvenlafaxine is further metabolized by CYP3A4. ${ }^{122}$ Other metabolic pathways for venlafaxine include $\mathrm{N}$-demethylation which is probably mediated by CYP3A4. ${ }^{157}$ CYP2C 9 and CYP2C19 isoenzymes may also be involved in the metabolic pathways of both drugs. ${ }^{121}$

In contrast with desvenlafaxine, the CYP2D6 genetic polymorphism has a significant influence on venlafaxine pharmacokinetics. ${ }^{122}$ Both drugs may have low potential for drug interactions, because of low protein binding and a relatively weak inhibitory effect on CYP isoenzymes. ${ }^{90,123}$ Nevertheless, increased plasma levels of imipramine, its metabolite desimipramine, ${ }^{124}$ and risperidone were associated with concomitant administration of venlafaxine. ${ }^{125}$ Furthermore, diphenhydramine may alter the disposition of venlafaxine via inhibition of CYP2D6. ${ }^{126}$ CYP3A4 inducers may enhance the clearance rate of desvenlafaxine. ${ }^{122}$

Venlafaxine and desvenlafaxine are primarily excreted via the renal route. ${ }^{157,127}$ About $29 \%$ of a venlafaxine dose is excreted as the active metabolite. ${ }^{156,128}$ Both venlafaxine and 
desvenlafaxine are rapidly eliminated, and steady-state plasma concentrations are reached within three days. Both drugs show linear pharmacokinetics in the therapeutic range. ${ }^{157}$

Age and gender differences are not clinically significant and require no dose adjustment for either drug. ${ }^{129}$ Disposition of venlafaxine and desvenlafaxine may be affected by renal impairment, and a reduction in venlafaxine dose is recommended for patients with creatinine clearance rates $<30 \mathrm{~mL} / \mathrm{min} .{ }^{157,166}$ Moreover, due to altered metabolism, patients with mild to moderate hepatic impairment require dose adjustment of venlafaxine and desvenlafaxine (see Table 3). ${ }^{157}$

Superior efficacy of venlafaxine compared with placebo and efficacy similar to that of the TCAs in major depression was reported. ${ }^{22,130,131}$ However, venlafaxine was superior to TCAs in treatment-resistant depression. ${ }^{170}$ Controversial reports exist concerning the relative efficacy of venlafaxine and SSRIs. Comparison of venlafaxine with sertraline and escitalopram showed similar efficacy in the treatment of severe depressive disorders. ${ }^{76,80,132}$ Comparable efficacy has also been reported for venlafaxine, fluoxetine, paroxetine, and fluvoxamine. ${ }^{22,133}$ However, some authors observed superior efficacy of venlafaxine compared with duloxetine, fluoxetine, fluvoxamine, paroxetine, and reboxetine (see Table 1), ${ }^{79,134,135}$ while others found only increased efficacy compared with fluoxetine among the second-generation antidepressants. ${ }^{136}$ Higher remission rates were observed with venlafaxine compared with SSRIs and placebo. ${ }^{172}$ Long-term venlafaxine treatment was effective in reducing relapse after a major depressive episode. ${ }^{170}$

Despite the conflicting evidence, venlafaxine may be a cost-effective alternative to fluoxetine and amitriptyline when used as first-line therapy. ${ }^{137}$ Venlafaxine XR is also probably one of the best alternatives for patients who do not benefit from SSRIs. ${ }^{46,172}$ Overall response and remission rates in major depression were significantly better with desvenlafaxine $50-100 \mathrm{mg}$ compared with placebo. ${ }^{138}$

Venlafaxine is better tolerated than TCAs, but may cause a broader array of adverse events, such as dry mouth, constipation, increased pulse, and increased heart rate compared with the SSRIs. ${ }^{46,139}$ The blood pressure increase seems to be dosedependent, and ranges from $2 \%$ at doses of $75-150 \mathrm{mg} /$ day to $10 \%$ for $300 \mathrm{mg} /$ day. $^{22,140,178}$ Discontinuation syndrome, characterized by nausea, insomnia, chills, irritability, and paresthesias may occur when venlafaxine is stopped abruptly (see Table 1). This syndrome may be suppressed by switching to fluoxetine or tapering venlafaxine prior to withdrawal. ${ }^{140}$ Furthermore, overdose with venlafaxine may be more serious than with the SSRIs. ${ }^{46,141}$ Tolerability is dose-dependent and may be improved by slower titration to higher doses. ${ }^{142}$

Desvenlafaxine has an acceptable safety and tolerability profile. ${ }^{143}$ A strong dose-response effect on tolerability was reported, but both $50 \mathrm{mg}$ and $100 \mathrm{mg}$ doses were well tolerated. ${ }^{144,177}$ Discontinuation rates due to adverse events were similar to those with placebo. The most common adverse event was transient mild to moderate nausea. Changes in mean blood pressure were small but statistically significant. Erectile dysfunction in man and anorgasmia in women were the most common sexual adverse events. ${ }^{144}$

The usual dose of venlafaxine IR is $75-375 \mathrm{mg} /$ day and $75-225 \mathrm{mg}$ /day for venlafaxine XR. ${ }^{46} \mathrm{With}$ rapid venlafaxine dose escalation up to $375 \mathrm{mg} /$ day, onset of efficacy can be achieved after only one week. ${ }^{145}$ Use of higher doses may also improve response in treatment-resistant depression. However, higher venlafaxine doses (300-375 mg/day) were associated with poorer tolerability. ${ }^{182}$ The usual dose of desvenlafaxine ranges from 50-100 mg once daily, although doses higher than $50 \mathrm{mg}$ showed no evidence of better efficacy. ${ }^{46,184}$

\section{Duloxetine}

Duloxetine is an inhibitor of serotonin and noradrenaline reuptake, with more than 100-fold greater potency compared with venlafaxine. ${ }^{146}$ Duloxetine has low affinity for $\mathrm{D}_{2}$, serotonin, $\alpha_{1}$ - and $\alpha_{2}$-adrenergic, muscarinic, $H_{1}$, and opioid receptors. Duloxetine does not inhibit gamma-amino butyric acid, choline transporters, MAO-A or MAO-B. ${ }^{187}$

Duloxetine is absorbed within six hours following oral administration. ${ }^{147}$ This process may be delayed by food and decreased by evening administration. ${ }^{148}$ The drug has high protein binding and a high volume of distribution (see Table 2). ${ }^{149,150}$

Extensive metabolism, predominantly via CYP1A2, to a lesser extent via CYP2D6, and at a very low rate via CYP2C $9,{ }^{151,152}$ has been reported, but the metabolites have no significant activity. ${ }^{153}$ Duloxetine is a moderate CYP2D6 inhibitor and may inhibit its own metabolism ${ }^{154,155}$ as well as the metabolism of CYP2D6 substrates, such as desimipramine. ${ }^{90,195}$ The inhibition or induction of CYP1A2 is not clinically important, and coadministration of duloxetine with CYP1A2 substrates does not necessitate their dose adjustment. ${ }^{193}$ However, potent inhibitors of CYP2D6 and CYP1A2 may result in enhanced duloxetine concentrations and a need for dose adjustment. ${ }^{191,193}$

Due to high protein binding, duloxetine may displace other extensively protein-bound drugs, such as warfarin. ${ }^{191}$ Elimination of the drug is rapid and primarily via urine and 
feces. ${ }^{192}$ Steady state is reached in three days. ${ }^{190}$ Duloxetine has linear pharmacokinetics in the therapeutic range. ${ }^{194}$

Female gender and nicotine use have been associated with higher duloxetine plasma levels. ${ }^{196}$ Hispanic patients had a higher volume of distribution and delayed absorption compared with non-Hispanics. ${ }^{196}$ Clearance decreases with increasing age, although this effect is small. ${ }^{196}$ Hepatic impairment decreases the clearance of duloxetine, and dose adjustment is necessary in patients with liver disease (see Table 3)..$^{156}$

At doses of 40-120 mg/day, duloxetine shows superior efficacy compared with placebo in short-term studies ( $\leq 15$ weeks). ${ }^{198-201}$ The efficacy of duloxetine in the treatment of painful somatic vegetative symptoms in patients with MDD is questionable. ${ }^{157,158}$

Duloxetine had better efficacy than paroxetine or fluoxetine only in patients with severe depression (see Table 1). ${ }^{159}$ The drug showed no significant difference in efficacy compared with venlafaxine,${ }^{160}$ but a lower risk of increased blood pressure and fewer discontinuation symptoms when treatment was stopped. ${ }^{204,161}$ Compared with escitalopram, similar onset and efficacy of duloxetine (60-120 mg/day) has been observed. ${ }^{162,163}$ In contrast, a meta-analysis reported that escitalopram, mirtazapine, sertraline, and venlafaxine were significantly more efficacious than duloxetine. ${ }^{79}$

Generally, duloxetine is well tolerated both in short-term and long-term treatment of MDD (see Table 1). ${ }^{179,191,199,201}$ The incidence of most common side effects may be dosedependent. ${ }^{164}$ Long-term treatment has a minimal effect on body weight, ${ }^{165}$ whereas short-term treatment is associated with modest effects on blood pressure and heart rate, no clinically significant effect on Electrocardiogram profiles, ${ }^{166}$ an increased incidence of sexual dysfunction, ${ }^{167}$ and an increased risk of higher serum transaminase levels. ${ }^{209}$

The safety and tolerability profile of duloxetine $40-120 \mathrm{mg} /$ day is similar to that of paroxetine $20 \mathrm{mg} /$ day. ${ }^{168}$ However, duloxetine is less well tolerated than escitalopram. ${ }^{207,208}$ Patients on duloxetine experience higher rates of insomnia and constipation. ${ }^{207}$ Furthermore, Cipriani et al reported poorer tolerability of duloxetine compared with sertraline. ${ }^{67}$ Higher discontinuation rates were observed with duloxetine due to adverse events compared with venlafaxine. Nausea and dizziness were more frequent in patients on duloxetine, while patients on venlafaxine experienced significantly greater elevation of systolic blood pressure. ${ }^{204}$
The usual starting dose is $40 \mathrm{mg} /$ day ( $20 \mathrm{mg}$ twice daily) to $60 \mathrm{mg} /$ day ( $30 \mathrm{mg}$ twice daily or $60 \mathrm{mg}$ once daily) in the US and $60 \mathrm{mg}$ once daily in the European Union. ${ }^{191}$

\section{Milnacipran}

Milnacipran inhibits noradrenaline and serotonin uptake at presynaptic sites. ${ }^{169}$ Despite the high affinity for both serotonin and noradrenaline transporters, noradrenaline reuptake is preferentially blocked. ${ }^{170}$ Postsynaptic cholinergic, adrenergic, $\mathrm{H}_{1}, \mathrm{D}_{2}$, and serotonergic receptors are not affected. ${ }^{171,172}$

Following oral administration the onset of absorption is delayed. ${ }^{173}$ Bioavailability is high and not affected by food. ${ }^{174,218}$ Milnacipran has low protein binding and extensive distribution in the body. ${ }^{219,174}$ The drug undergoes oxidative biotransformation via CYP3A4 and conjugation. ${ }^{219}$ Only one of three metabolites has pharmacologic activity, but the concentrations are $<1 \%$ of the parent compound. The risk of pharmacokinetic drug-drug interactions may be low. ${ }^{175,219}$ Moreover, induction or inhibition of CYP2D6 or CYP2C19 has no significant effect on milnacipran. ${ }^{175}$

Due to potential pharmacodynamic interactions, milnacipran is contraindicated in patients receiving MAOIs. Concomitant administration of drugs that may influence serotonin metabolism, such as tramadol, triptanes, and linezolid, is not recommended or requires caution due to potential serotonin syndrome. Coadministration with digoxin may result in potentiation of hemodynamic effects, whereas coadministration with adrenaline and noradrenaline may be associated with paroxysmal hypertension and possibly arrhythmia. $^{218}$

Milnacipran elimination is rapid and predominantly renal. ${ }^{218,219}$ Steady-state concentrations are reached within a few days. ${ }^{215,221}$ The drug shows linear pharmacokinetics over the therapeutic dose range (see Table 2). ${ }^{218}$

Age and gender influence milnacipran plasma levels but dose adjustment is not necessary. ${ }^{218}$ Milnacipran should be administered with caution in patients with severe hepatic or moderate to severe renal impairment (see Table 3). ${ }^{176,215,218,220}$

Milnacipran $50 \mathrm{mg}$ was significantly more effective than placebo in the treatment of MDD. ${ }^{176,177}$ Comparison of milnacipran with other antidepressants, such as SSRIs and TCAs, demonstrated no significant differences in clinical response or remission rates in the acute phase. ${ }^{178,179} \mathrm{Cipriani}$ et al reported better scores for mirtazapine, escitalopram, venlafaxine, sertraline, and citalopram, than for milnacipran. In contrast, 
milnacipran scored better than bupropion, duloxetine, fluvoxamine, paroxetine, fluoxetine, and reboxetine. ${ }^{67}$

Milnacipran is generally well tolerated (see Table 1). ${ }^{180,226}$ Milnacipran may be superior to TCAs and SSRIs in terms of need for premature treatment withdrawal due to adverse events. Patients who experienced adverse effects from other antidepressants in the acute phase of treatment may benefit from this drug. ${ }^{228}$

Cipriani et al reported better tolerability scores for escitalopram, sertraline, bupropion, and citalopram compared with milnacipran. In contrast, milnacipran scored better than mirtazapine, fluoxetine, venlafaxine, duloxetine, fluvoxamine, paroxetine, and reboxetine. ${ }^{67}$

The usual dose range for milnacipran is $100-200 \mathrm{mg} /$ day. ${ }^{46}$ Titration of the dose is recommended. The initiation dose should be $12.5 \mathrm{mg}$ on the first day and $12.5 \mathrm{mg}$ twice daily on the second and third days, $25 \mathrm{mg}$ twice daily on the fourth to seventh days, and $50 \mathrm{mg}$ twice daily thereafter. Based on individual response, the dose should be increased to $100 \mathrm{mg}$ twice daily. ${ }^{218}$

\section{Reboxetine}

Reboxetine is a potent, selective, and specific noradrenaline reuptake inhibitor, with negligible affinity for muscarinic, $\mathrm{H}_{1}, \alpha_{1}$, and $\mathrm{D}_{2}$ receptors. ${ }^{180}$

Reboxetine has two chiral centers, but only the (R,R)-(-)and $(\mathrm{S}, \mathrm{S})-(+)$-enantiomer is present in the marketed product. Some studies suggest that both the therapeutic and adverse effects are related predominantly to $(\mathrm{S}, \mathrm{S})-(+)$ reboxetine. ${ }^{181}$

Reboxetine is absorbed rapidly and almost completely after oral administration. ${ }^{182,183}$ Food delays but does not influence the extent of absorption (see Table 2) ${ }^{184}$ Reboxetine is extensively bound to plasma proteins and has a moderate distribution volume compared with other antidepressants. ${ }^{231-233}$ Metabolism occurs principally via CYP3A4. ${ }^{231}$ Each enantiomer is metabolized to the primary metabolite O-desethylreboxetine, and three other metabolites. ${ }^{185}$ Reboxetine is probably not an inhibitor of CYP isoenzymes. ${ }^{186,231}$

The drug has a moderate half-life and low clearance. ${ }^{231,232}$ Reboxetine exhibits linear pharmacokinetics in the therapeutic range. ${ }^{231}$ After multiple doses, steady state is achieved within four days. ${ }^{231}$

Ethnicity seems to influence reboxetine pharmacokinetics but dose adjustment is not necessary. ${ }^{186}$ Plasma levels are higher and more variable in elderly patients, and therefore treatment with reboxetine should be initiated at a lower dose. ${ }^{187,188}$ The elimination rate of reboxetine decreases as renal function declines. ${ }^{189}$ Elimination is also slower in patients with hepatic dysfunction, but the degree of dysfunction does not affect reboxetine pharmacokinetics (see Table 3). ${ }^{190}$

In short-term studies (4-6 weeks) reboxetine showed superior efficacy compared with placebo in primary and secondary outcomes. ${ }^{242-244}$ Overall, reboxetine scored significantly better in mean responder rate and relapse rates compared with placebo (see Table 1). ${ }^{191,192,242}$ Compared with imipramine, the efficacy of reboxetine was similar in adults ${ }^{193}$ and elderly patients, ${ }^{194}$ but reboxetine had significant advantages in the treatment of melancholic patients. ${ }^{195}$ Similar efficacy of reboxetine and fluoxetine was reported, but reboxetine was more effective in a subgroup of severely depressed patients. ${ }^{196,197}$ Moreover, social functioning was better in patients who achieved remission with reboxetine. ${ }^{250}$

Nevertheless, Cipriani et al suggested that reboxetine was significantly less effective than bupropion, citalopram, duloxetine, escitalopram, fluoxetine, fluvoxamine, milnacipran, mirtazapine, paroxetine, sertraline, and venlafaxine. ${ }^{79}$

The drug showed a good safety and tolerability profile (see Table 1). ${ }^{242}$ Reboxetine and imipramine had similar tolerability in adults and the elderly. Frequency of discontinuation due to adverse events was lower in the reboxetine group, whereas cumulative risk of hypotension, dry mouth, and tremor was significantly higher in the imipramine group. ${ }^{247}$ Reboxetine patients had a lower risk of serious adverse events, adverse event-related withdrawals, and treatmentrelated adverse events. ${ }^{248}$ The overall score of reboxetine for safety and tolerability was better than TCAs.

The adverse event profile of reboxetine is different to that of the SSRIs. Patients on reboxetine experienced less agitation, nervousness, anxiety, and gastrointestinal events compared with those on fluoxetine. Reboxetine was not associated with an increased risk of seizures, orthostatic hypotension, or cardiotoxicity, ${ }^{250}$ but had poorer tolerability than other antidepressants, including bupropion, citalopram, escitalopram, fluoxetine, and sertraline. ${ }^{79}$

Nevertheless, reboxetine is considered safe when administered at doses of $8-10 \mathrm{mg} /$ day to adult (18-65 years) and at $4-6 \mathrm{mg} /$ day to elderly ( $>65$ years) patients..$^{242}$

The recommended therapeutic dose for adults is $4 \mathrm{mg}$ twice daily ( $8 \mathrm{mg}$ /day). The dose can be increased to $10 \mathrm{mg}$ /day after three weeks if there is an inadequate clinical response. The recommended dose for the elderly ( $>65$ years) is $2 \mathrm{mg}$ bid ( $4 \mathrm{mg} /$ day) and, if necessary, the dose can be increased 
to $6 \mathrm{mg} /$ day. The same strategy is used for patients with renal impairment or moderate to severe hepatic insufficiency. ${ }^{242}$

\section{Agomelatine}

Agomelatine is an antagonist of serotonin $5 \mathrm{HT}_{2 \mathrm{~B}}$ and $5 \mathrm{HT}_{2 \mathrm{C}}$ receptors and a potent agonist of melatonergic $\mathrm{MT}_{1}$ and $\mathrm{MT}_{2}$ receptors. ${ }^{198,199}$ Serotonin outflow is not affected, but due to $5 \mathrm{HT}_{2 \mathrm{C}}$ antagonism, overflows of dopamine and noradrenaline are produced in the frontal cortex. ${ }^{200}$ The drug received marketing authorization for Europe in 2009 and is awaiting Federal Drug Administration approval in the US.

After oral administration, more than $78 \%$ of the dose is rapidly absorbed. ${ }^{254}$ Agomelatine is highly protein-bound and moderately distributed (see Table 2). ${ }^{253}$

Metabolism to inactive hydroxylated and demethylated metabolites is mediated primarily by CYP1A2 and to a less degree by CYP2C9 and CYP2C19. ${ }^{201}$ There is a lack of data about potential drug interactions, and this requires further investigation. The metabolites are excreted mainly in urine and feces. ${ }^{253,254}$ Elimination rate is very fast and steady-state concentrations are reached rapidly. ${ }^{253}$

The bioavailability of agomelatine may be increased in women and reduced in smokers. ${ }^{255}$ There are limited data about the pharmacokinetics of agomelatine in the elderly and in patients with renal impairment. Nevertheless, systemic exposure to agomelatine is increased in patients with hepatic impairment (see Table 3). ${ }^{253,255}$

Agomelatine significantly improved response rates and time to first response compared with placebo in 212 outpatients who received 25 or $50 \mathrm{mg} /$ day. ${ }^{202}$ Moreover, the onset of response with agomelatine was faster (two weeks) compared with paroxetine (four weeks). ${ }^{203}$ Higher efficacy than placebo was observed in patients with severe depression and efficacy increased with increasing severity of depression. ${ }^{204}$ Agomelatine $50 \mathrm{mg} /$ day and venlafaxine $75-150 \mathrm{mg} /$ day had similar response rates after 6-12 weeks. ${ }^{205,206}$

Agomelatine was generally well tolerated, with a good safety profile (see Table 1). ${ }^{256}$ Compared with venlafaxine, the agomelatine treatment group experienced less frequent sexual dysfunction and orgasmic dysfunction. ${ }^{259}$ Safety profile was generally better compared with current standard treatments, including absence of serotonin syndrome, weight gain, and a low incidence of sexual dysfunction and gastrointestinal adverse effects. ${ }^{252}$ Abrupt cessation of agomelatine was not associated with discontinuation symptoms. ${ }^{207}$

Despite encouraging results for the safety and tolerability of agomelatine, there is still a lack of data regarding its efficacy which requires further investigation. The usual initiating dose is $25 \mathrm{mg} /$ day which may be increased if necessary to $50 \mathrm{mg} /$ day. ${ }^{253}$

\section{Aripiprazole}

Aripiprazole is an atypical antipsychotic approved as a adjunct treatment for MDD. The probable mechanism of antidepressant action is partial agonism at $\mathrm{D}_{2}, \mathrm{D} 3$, and $5-\mathrm{HT}_{1 \mathrm{~A}}$ receptors and antagonistic activity at $5-\mathrm{HT}_{2 \mathrm{~A}}$ receptors. Moderate affinity was also found for D4, 5 - $\mathrm{HT}_{2 \mathrm{C}}, 5-\mathrm{HT}_{7}, \alpha 1$-adrenergic, and $\mathrm{H}_{1}$ receptors, whereas the activity at muscarinic and cholinergic receptors was minimal. ${ }^{208}$

Aripiprazole is well absorbed following oral administration. Food prolonged the time of absorption for approximately three hours but did not affect extent of absorption (see Table 2). The drug is almost completely bound to plasma proteins. Following metabolism mediated by CYP3A4 and CYP2D6, the active metabolite, dehydroaripiprazole, is formed. Genetic polymorphism of CYP2D6 has a significant influence on aripiprazole plasma levels, and poor metabolizers have an approximately $60 \%$ increased exposure to the drug. Aripiprazole has low inhibitory potential for CYP450 isoenzymes. No relevant interactions were observed after coadministration of the drug with SSRIs and venlafaxine. In contrast, concomitant administration of CYP3A4 inducers may require increased doses of aripiprazole whereas concomitant administration of CYP2D6 or CYP3A4 inhibitors may require dose reduction for aripriprazole. ${ }^{262}$

Aripiprazole is eliminated slowly, therefore takes about two weeks to reach steady state. Urine and feces are the main elimination routes. ${ }^{262} \mathrm{Age}$, race, gender, smoking status, and hepatic and renal function showed no clinically relevant effects on aripiprazole pharmacokinetics. ${ }^{262}$

A meta-analysis of clinical efficacy trials of aripiprazole $(2-20 \mathrm{mg} /$ day $)$ revealed increased response rates of $8 \%$ and increased remission rates of $10 \%$ when the drug was used as adjuvant antidepressant medication compared with placebo in patients with MDD (see Table 1). ${ }^{209,210}$ However, the absolute difference in the efficacy outcome between aripiprazole and placebo was relatively low, and therefore the clinical significance of the findings is debatable. ${ }^{211,212}$ Because augmentation is used in patients who have failed to respond to monotherapy, evaluation of clinical relevance is difficult and further studies are necessary.

The most common adverse effects of aripiprazole are presented in Table 1. Discontinuation of treatment due to 
adverse effects was rarely observed, and no serious adverse effects were reported..$^{263,264}$

The starting dose for adjunctive aripiprazole treatment should be $2-5 \mathrm{mg} /$ day. If necessary, a weekly dose increase is recommended up to $15 \mathrm{mg} /$ day. The drug is not approved for the treatment of patients with dementia-related psychosis or depressive pediatric patients. ${ }^{262}$ Further investigations with aripiprazole are necessary to establish its full potential in the treatment of MDD.

\section{Emergence of new therapeutic agents}

Vilazodone is a serotonin reuptake inhibitor and a partial $5-\mathrm{HT}_{1 \mathrm{a}}$ agonist. This drug is currently under clinical evaluation for the treatment of major depression and awaiting approval by the Federal Drug Administration. So far, results for the clinical efficacy of vilazodone in depressed patients have been conflicting. A large Phase II trial including more than 1000 depressed patients failed to show efficacy of the drug over placebo. ${ }^{213}$ In contrast, a Phase III trial which included 410 patients with MDD revealed superior efficacy of viladozone (10-40 mg/day) over placebo in primary and secondary outcomes within eight weeks. ${ }^{214}$ Vilazodone was well tolerated, and adverse effects were mild to moderate, including nausea, somnolence, diarrhea, and dizziness.

Serotonin, noradrenaline, and dopamine (triple) reuptake inhibitors are in process of development, ${ }^{215}$ and most are now in Phase II clinical trials. ${ }^{216}$ Some of these drugs (eg, DOV 21947) show significantly higher efficacy compared with placebo and similar efficacy to citalopram. ${ }^{269}$ In contrast, lack of improved efficacy resulting in discontinued development (NS-2359) was also reported. ${ }^{217}$

Drugs that antagonize $\alpha_{2}$-adenoreceptors and suppress reuptake of serotonin or noradrenaline or both (S35966 and R226161) may have a faster onset of effect, and improve cognition and sexual function. However, adverse effects comprising increased arterial pressure and tachycardia were reported. ${ }^{218,219,267}$

Dual-acting serotonin reuptake inhibitors and $\mathrm{H}_{3}$ antagonists (eg, JNJ-2583867) may improve mood and cognitive impairment in depression and have a low risk of obesity. A possible disadvantage of these substances may be their wake-inducing action. ${ }^{220,267}$

Some emerging evidence suggests that several families of glutamate receptors may be potential targets for new antidepressants. ${ }^{267,269} \mathrm{CP}-10-606$, an N-methyl-D-aspartic acid antagonist, significantly improved depressive symp- toms compared with placebo. ${ }^{269}$ There are some suggestions that positive allosteric modulators at $\alpha$-amino-3-hydroxy5-methyl-4-isoxazolepropionic acid receptor (AMPA) receptors may be useful in the clinical management of depression. ${ }^{267,269}$ However, clinical data on these agents are not yet available. ${ }^{269}$

Riluzole, a glutamate-modulating agent, approved for treatment of amyotrophic lateral sclerosis, showed antidepressant properties and was well tolerated. ${ }^{221,269}$ However, its role as monotherapy or augmentation of standard therapy remains to be established.

Metyrapone, an inhibitor of cortisol synthesis, may become a possible adjunctive agent for major depression. ${ }^{269}$ Also, a strong antagonist of the Type II glucocorticoid receptor, mifepristone (RU486) was suggested as adjunctive treatment for psychotic depression. ${ }^{269}$ However, pivotal Phase III studies of mifepristone in MDD with psychotic features have had discouraging results. ${ }^{269}$

\section{Compliance}

One of the major obstacles to effective management of depression is poor compliance. ${ }^{220}$ Sawada et al found that only $44.3 \%$ patients continued antidepressant treatment after six months. Moreover, $63.1 \%$ patients who discontinued therapy did so without consulting their physicians. ${ }^{221}$

Reasons for treatment discontinuation are multifactorial. Symptoms of depression such as poor concentration and motivation may predispose patients to noncompliance. Early withdrawals are usually due to adverse events or lack of efficacy. However, later dropouts are usually due to patients feeling better or fearing drug addiction. Studies suggest men are more likely to discontinue antidepressant therapy than women following initial treatment efficacy. ${ }^{276}$

Choice of an adequate, effective, and well tolerated drug with optimal formulation, as well as effective communication between patient and health professionals, are important for successful treatment. The newer, more selective antidepressants may have better tolerability and hence better compliance. ${ }^{277}$ Moreover, drugs with a longer half-life and once-daily dosing schedules will improve patient compliance. ${ }^{276,277}$ Patients suggest that information about adverse events and likely duration of treatment may significantly improve compliance. Well informed patients are less likely to discontinue treatment and more likely to switch drug if necessary. ${ }^{222,223}$ 


\section{Conclusion}

MDD is a complex disease and requires a multifaceted approach for research, diagnosis, and treatment. Modern classes of antidepressants such as SSRIs, serotonin/noradrenaline reuptake inhibitors, and noradrenaline/dopamine reuptake inhibitors offer superior tolerability and safety over older medications like the TCAs and MAOIs. However, the choice among newer antidepressants is difficult, given that all of them showed more or less similar efficacy and good tolerability. Nevertheless, individual patient preferences related to adverse effect profiles and cost of treatment, as well as adjusting the regimen appropriately, may provide the best approach. If a single drug fails, combined treatment with antidepressants having different modes of action may improve treatment efficacy. However, with such approach, the increased risk of interactions should be considered.

It is clear that there are substantial limitations in current antidepressant pharmacotherapy and there is a need for new therapeutic approaches. Advances in understanding the neurobiology of depression have opened up a new era of investigations with novel therapeutic approaches and compounds based on new mechanisms of action. Today, research is focused on a variety of targets such as the L-arginine-nitric oxide-cyclic guanosine monophosphate pathway, the endocannabinoid system, sigma-1 receptors, melatonin, 5- $\mathrm{HT}_{6}$ and $5-\mathrm{HT}_{7}$ receptor antagonists, $\beta_{3}$ adrenergic antagonists, vasopressin receptor antagonists, and $\mathrm{NK}_{2}$ tachykinin receptor antagonists. Although the potential efficacy of these agents remains to be established, the future of antidepressant treatment appears to be promising.

\section{Acknowledgment}

We would like to thank the Ministry of Science, Belgrade, Republic of Serbia (Project No 145001) for its support.

\section{Disclosure}

The authors report no conflict of interest in this work.

\section{References}

1. Pratt LA, Brody DJ. Depression in the United States household population, 2005-2006. NCHS Data Brief. 2008;7:1-8.

2. Kessler RC, Berglund P, Demler O, et al. The epidemology of major depressive disorder: Results from the National Comorbidity Survey Replication (NCS-R). JAMA. 2003;289(23):3095-3105.

3. Ebmeier KP, Donaghey JC, Steele JD. Recent developments and current controversies in depression. Lancet. 2006;367(9505): 153-167.

4. NIH Consensus Conference. Diagnosis and treatment of depression in late life. JAMA. 1992;268(8):1018-1024.

5. Rothschild AJ. The diagnosis and treatment of late-life depression. J Clin Psychiatry. 1996;57(5):5-11.
6. Steffens DC, Skoog I, Norton MC, et al. Prevalence of depression and its treatment in an eldery population: The Cache County study. Arch Gen Psychiatry. 2000;57(6):601-607.

7. Belmaker RH, Agam G. Major depressive disorder: Mechanisms of disease. N Engl J Med. 2008;358(1):55-68.

8. Jain R. The implication of pain and physical symptoms in depression. J Clin Psychiatry. 2009;70(6):e19.

9. aan het Rot M, Mathew SJ, Charney DS. Neurobiological mechanisms in major depressive disorder. CMAJ. 2009;180(3):305-313.

10. Caspi A, Sugden K, Moffitt TE, et al. Influence of life stress on depression: Moderation by a polymorphism in the 5-HTT gene. Science. 2003; 301(5631):386-389.

11. Hansenne M, Bianchi J. Emotional intelligence and personality in major depression: Trait versus state effects. Psychiatry Res. 2009; 166(1):63-68.

12. Zhang X, Gainetdinov RR, Beaullieu JM, et al. Loss-of-function mutation in tryptophan hydroxylase-2 identified in unipolar major depression. Neuron. 2005;45(1):11-16.

13. Pitchot W, Hansenne M, Pinto E, Reggers J, Fuchs S, Ansseau M. 5-Hydroxytryptamine $1 \mathrm{~A}$ receptor, major depression, and suicidal behavior. Biol Psychiatry. 2005;58(11):854-858.

14. Svenningson P, Chergui K, Rachleff I, et al. Alterations in 5-HT1B receptor function by 11 in depression-like states. Science. 2006; 311(5757):77-80.

15. Ordway GA, Schenk J, Stockmeier CA, May W, Klimek V. Elevated agonist binding to alpha 2-adrenoceptors in the locus coeruleus in major depression. Biol Psychiatry. 2003;53(4): 315-323.

16. Coupland NJ, Ogilvie CJ, Hegadoren KM, Seres P, Hanstock CC, Allen PS. Decreased prefrontal myo-inositol in major depressive disorder. Biol Psychiatry. 2005;57(12):1526-1534.

17. Valdizan EM, Gutierrez O, Pazos A. Adenylate cyclase activity in postmortem brain of suicide subjects: Reduced response to beta-adrenergic stimulation. Biol Psychiatry. 2003;54(12):1457-1464.

18. Blendy JA. The role of CREB in depression and antidepressant treatment. Biol Psychiatry. 2006;59(12):1144-1150.

19. Mann JJ. The medical management of depression. $N$ Engl J Med. 2005;353(17):1819-1834.

20. Vreeburg SA, Hoogendijk WJ, van Pelt J, et al. Major depressive disorder and hypothalamic-pituitary-adrenal axis activity: Results from a large cohort study. Arch Gen Psychiatry. 2009;66(6):617-626.

21. Burke HM, Davis MC, Otte C, Mohr DC. Depression and cortisol responses to psychological stress: A meta-analysis. Psychoneuroendocrinology. 2005;30(9):846-856.

22. Baghai TC, Volz HP, Moller HJ. Drug treatment of depression in the 2000s: An overview of achievements in the last 10 years and future possibilities. World J Biol Psychiatry. 2006;7(4):198-222.

23. MacQueen GM, Campbell S, McEwen BS, et al. Course of illness, hippocampal function, and hippocampal volume in major depression. Proc Natl Acad Sci U SA. 2003;100(3):1387-1392.

24. Karege F, Vaudan G, Schwald M, Perroud N, La Harpe R. Neurotrophin levels in postmortem brains of suicide victims and the effects of antemortem diagnosis and psychotropic drugs. Brain Res Mol Brain Res. 2005; 136(1-2):29-37.

25. Sanacora G, Zarate CA, Krystal JH, Manji HK. Targeting the glutamatergic system to develop novel, improved therapeutics for mood disorders. Nat Rev Drug Discov. 2008;7(5):426-437.

26. Hasler G, van der Veen JW, Tumonis T, Mayers N, Shen J, Drevets WC. Reduced prefrontal glutamate/glutamine and gamma-aminobutyric acid levels in major depression determined using proton magnetic resonance spectroscopy. Arch Gen Psychiatry. 2007;64(2): 193-200.

27. Lewy AJ, Lefler BJ, Emens JS, Bauer VK. The circadian basis of winter depression. Proc Natl Acad Sci U S A. 2006;103(19): 7414-7419.

28. Beasley CL, Honer WG, Bergmann K, Faikai P, Lutjohann D, Bayer TA. Reductions in cholesterol and synaptic markers in association cortex in mood disorders. Bipol Disord. 2005;7(5):449-455. 
29. Kennedy SE, Koeppe RA, Young EA, Zubeita JK. Dysregulation of endogenous opoid emotion regulation circuitry in major depression in women. Arch Gen Psychiatry. 2006;63(11):1199-1208.

30. Janowsky DS, Overstreet DH. Cholinergic-muscarinic dysfunction in mood disorders. In: Soares JC, Young AH, editors. Bipolar Disorders. Basic Mechanisms and Therapeutic Implications. 2nd ed. New York, NY: Informa Healthcare; 2007.

31. Sullivan GM, Mann JJ, Oquendo MA, Lo ES, Cooper TB, Gorman JM. Low cerebrospinal fluid transthyretin levels in depression: Correlations with suicidal ideation and serotonin function. Biol Psychiatry. 2006;60(5):500-506.

32. Milak MS, Parsey RV, Keilp J, Oquendo MA, Malone KM, Mann JJ. Neuroanatomic correlates of psychopathologic components of major depressive disorder. Arch Gen Psychiatry. 2005;62(4): 397-408.

33. Nemeroff CB, Heim CM, Thase ME, et al. Differential response to psychotherapy versus pharmacotherapy in patients with chronic forms of major depression and childhood trauma. Proc Natl Acad Sci U SA. 2003;100(24):14293-14296.

34. Imel ZE, Malterer MB, McKay KM, et al. A meta-analysis of psychotherapy and medication in unipolar depression and dysthymia. JAffect Disord. 2008;110(3):197-206.

35. Krishan KR. Revisiting monoamine oxidase inhibitors. JClin Psychiatry. 2007;68(Suppl 8):S35-S41.

36. Fiedorowicz JG, Swartz KL. The role of monoamine oxidase inhibitors in current psychiatric practice. $J$ Psychiatr Pract. 2004; 10(4):239-248

37. Jessen L, Kovalick LJ, Azzaro AJ. The selegiline transdermal system (Emsam): A therapeutic option for the treatment of major depressive disorder. P T. 2008;33(4):212-246.

38. Gillman PK. Tricyclic antidepressant pharmacology and therapeutic drug interactions updated. Br J Pharmacol. 2007;151(6): 737-748.

39. Burke MJ, Preskorn SH. Therapeutic drug monitoring of antidepressants: Cost implications and relevance to clinical practice. Clin Pharmacokinet. 1999;37(2):147-165.

40. Billups SJ, Delate T, Dugan D. Evaluation of risk factors for elevated tricyclic antidepressant plasma concentrations. Pharmacoepidemiol Drug Saf. 2009;18(3):253-257.

41. Anderson IM. SSRI versus tricyclic antidepressants in depressed inpatients: A meta-analysis of efficacy and tolerability. J Affect Disord. 2000;58(1):19-36.

42. Gervasoni N, Aurby JM, Gex-Farby M, Bertschy G, Bondolfi G. Is there a place for tricyclic antidepressant and subsequent augmentation strategies in obtaining remission for patients with treatment resistant depression? Pharmacol Res. 2009;59(3): 202-206.

43. Koenig AM, Thase ME. First-line pharmacotherapies for depressionwhat is the best choice? Pol Arch Med Wewn. 2009;119(7-8): $478-486$.

44. Hiemke C, Hartter S. Pharmacokinetics of selective serotonin reuptake inhibitors. Pharmacol Ther. 2000;85(1):11-28.

45. Draper B, Bermen K. Tolerability of selective serotonin reuptake inhibitors. Drugs Aging. 2008;25(6):501-519.

46. Greenblatt DJ, von Moltke LL, Schmider J, Harmatz JS, Shader RI. Inhibition of human cytochrome P4503A isoforms by fluoxetine and norfluoxetine: In vitro and in vivo studies. $J$ Clin Pharmacol. 1996;36(9):792-798.

47. Owens MJ, Knight DL, Nemeroff CB. Second-generation SSRIs: Human monoamine transporter binding profile of escitalopram and $R$-fluoxetine. Biol Psychiatry. 2001;50(5):345-350.

48. Rao N. The clinical pharmacokinetics of escitalopram. Clin Pharmacokinet. 2007;46(4):281-290

49. Søgaard B, Mengel H, Rao N, Larsen F. The pharmacokinetics of escitalopram after oral and intravenous administration of single and multiple doses to healthy subjects. J Clin Pharmacol. 2005;45(12):1400-1406.
50. Sidhu J, Priskorn M, Poulsen M, Segonzac A, Grollier G, Larsen F. Steady-state pharmacokinetics of the enantiomers of citalopram and its metabolites in humans. Chirality. 1997;9(7):686-692.

51. Rochat B, Kosel M, Boss G, Testa B, Gillet M, Baumann P. Stereoselective biotransformation of the selective serotonin reuptake inhibitor citalopram and its demethylated metabolites by monoamine oxidase in human in human liver. Biochem Pharmacol. 1998;56(1): 15-23.

52. Kosel M, Gnerre C, Voirol P, et al. In vitro biotransformation of the selective serotonin reuptake inhibitor citalopram, its enantiomers and demethylated metabolites by monoamine oxidase in rat and human brain preparations. Mol Psychiatry. 2002;7(2):181-188.

53. Gutierrez MM, Rosenberg J, Abramowitz W. An evaluation of the potential for pharmacokinetic interaction between escitalopram and the cytochrome P450 3A4 inhibitor ritonavir. Clin Ther. 2003; 25(4):1200-1210.

54. Malling D, Poulsen MN, Sogaard B. The effect of cimetidine or omeprazole on the pharmacokinetics of escitalopram in healthy subjects. $\mathrm{Br}$ J Clin Pharmacol. 2005;60(3):287-290.

55. Joffe P, Larsen FS, Pedersen V, Larsen-Ring H, Jørgensen-Aaes T, Sidhu J. Single-dose pharmacokinetics of citalopram in patients with moderate renal insufficiency or hepatic cirrhosis compared with healthy subjects. Eur J Clin Pharmacol. 1998;54(39):237-242.

56. Periclou A, Rao N, Sherman T, Ventura D, Abramowitz W. Singledose pharmacokinetics study of escitalopram in adolescents and adults. Pharmacotherapy. 2003;23(10):1361-1362.

57. Cipriani A, Santilli C, Furukawa TA, et al. Escitalopram versus other antidepressive agents for depression. Cochrane Database Syst Rev. 2009; CD006532.

58. Emslie GJ, Ventura D, Korotzer A, Tourkodimitris S. Escitalopram in the treatment of adolescent depression: A randomized placebocontrolled multisite trial. J Am Acad Child Adolesc Psychiatry. 2009; 48(7):721-729.

59. Llorca PM, Azorin JM, Despiegel N, Verpillat P. Efficacy of escitalopram in patients with severe depression: A pooled analysis. Int J Clin Pract. 2005;59(3):268-275.

60. Svensson S, Mansfield PR. Escitalopram: Superior to citalopram or a chiral chimera? Psychother Psychosom. 2004;73(1):10-16.

61. Alexopoulos GS, Privitera W, Ventura D, Bose A, Wang Q. Doubleblind comparison of escitalopram $10 \mathrm{mg}$ /day and optimally-dosed sertraline 50-200 mg/day in the treatment of major depressive disorder. Poster presented at the 42nd annual meeting of the American College of Neuropsychopharmacology. San Juan, Puerto Rico, December 7-11, 2003

62. Kasper S, Baldwin DS, Lonn SL, Boulenger JP. Superiority of escitalopram to paroxetine in the treatment of depression. Eur Neuropsychopharmacol. 2009;19(4):229-237.

63. Montgomery SA, Moller HJ. Is the significiant superiority of escitalopram compared with other antidepressants clinically relevant? Int Clin Psychopharmacol. 2009;24(3):111-118.

64. Bielski RJ, Ventura D, Chang DD. A double-blind comparison of escitalopram and venlafaxine extended release in the treatment of major depressive disorder. J Clin Psychiatry. 2004;65(9):1190-1196.

65. Kennedy SH, Andersen HF, Thase ME. Escitalopram in the treatment of major depressive disorder: A meta-analysis. Curr Med Res Opin. 2009; 25(1):161-175

66. Kornstein SG, Li D, Mao Y, Larsson S, Andersen HF, Papakostas GI. Escitalopram versus SNRI antidepressants in the acute treatment of major depressive disorder: Integrative analysis of four double-blind, randomized clinical trials. CNS Spectr. 2009;14(6):326-333.

67. Cipriani A, Furukawa AT, Salanti G, et al. Comparative efficacy and acceptability of 12 new-generation antidepressants: A multipletreatments meta-analysis. Lancet. 2009;373(9665):746-758.

68. Montgomery SA, Huusom AKT, Bothmer J. A randomized study comparing escitalopram with venlafaxine XR in primary care patients with major depressive disorder. Neuropsychobiology. 2004;50(1): $57-64$. 
69. Bech P, Andersen HF, Wade A. Effective dose of escitalopram in moderate versus severe DSM-IV major depression. Pharmacopsychiatry. 2006;39(4):128-134.

70. Baldwin DS, Stein DJ, Dolberg OT, Bandelow B. How long should a trial of escitalopram treatment be in patients with major depressive disorder? An exploration of a randomized controlled trial database. Hum Psychopharmacol. 2009;24(4):269-275.

71. Croom KF, Perry CM, Plosker GL. Mirtazapine: A review of its use in major depression and other psychiatric disorders. CNS Drugs. 2009;23(5):427-452.

72. Anttila SAK, Leinonen EVJ. A review of the pharmacological and clinical profile of mirtazapine. CNS Drugs Rev. 2001:7(3): 249-264.

73. Voortman G, Paanakker JE. Bioavability of mirtazapine from Remeron ${ }^{\circledR}$ tablets after single and multiple oral dosing. Hum Psychopharmacol. 1995;10 Suppl 2:S83-S96.

74. Delbressine LPC, Moonen MEG, Kaspersen FM, et al. Pharmacokinetics and biotransformation of mirtazapine in human volunteers. Clin Drug Invest. 1998;15(1):45-55.

75. Spaans E, van den Heuvel MW, Schnabel PG, et al. Concomitant use of mirtazapine and phenytoin: A drug-drug interaction study in healthy male subjects. Eur J Clin Pharmacol. 2002;58(6): 423-429.

76. Ruwe FJ, Smulders RA, Kleijn HJ, et al. Mirtazapine and paroxetine: A drug-drug interaction study in healthy subjects. Hum Psychopharmacol. 2001;16(6):449-459.

77. Anttila AK, Rasanen L, Leinonen EV. Fluvoxamine augmentation increases serum mirtazapine concentrations three- to four-fold. Ann Pharmacother. 2001;35(10):1221-1223.

78. Sitsen JM, Maris FA, Timmer CJ. Concomitant use of mirtazapine and cimetidine: A drug-drug interaction study in healthy male subjects. Eur J Clin Pharmacol. 2000;56(5):389-394.

79. Grasmäder K, Verwohlt PL, Kühn KU, et al. Population pharmacokinetic analysis of mirtazapine. Eur J Clin Pharmacol. 2004; $60(7): 473-480$.

80. Brockmöller J, Meineke I, Kirchheiner J. Pharmacokinetics of mirtazapine: Enantioselective effects of the CYP2D6 ultra rapid metabolizer genotype and correlation with adverse effects. Clin Pharmacol Ther. 2007;81(5):699-707.

81. Timmer CJ, Lohmann AAM, Mink CPA. Pharmacokinetic dose-proportionality study at steady state of mirtazapine from Remeron ${ }^{\circledR}$ tablets. Hum Psychopharmacol. 1995;10 Suppl 2: S97-S106.

82. Lind AB, Reis, Bengtsson F, et al. Steady-state concetration of mirtazapine, N- desmethylmirtazapine, 8-hydroxymirtazapine and their enantiomers in relation to cytochrome P450 2D6 genotype, age and smoking behaviour. Clin Pharmacokinet. 2009;48(1):63-70.

83. Bengtsson F, Höglund P, Timmer C, Hegbrant J. Mirtazapine oral single dose kinetics in patients with different degrees of renal failure. Hum Psychopharmacol. 1998;13(5):357-365.

84. Organon USA Inc. Remeron (mirtazapine) tablets: US prescribing information (online). Avaliable from URL:http://www.organon.com Accessed May 5, 2010.

85. Montgomery SA, Reimitz PE, Zivkov M. Mirtazapine versus amitriptyline in long-term treatment of depression: A double-blind placebo-controlled study. Int Clin Psychopharmacol. 1998;13(2): 63-73.

86. Watanabe N, Omori IM, Nakagawa A, et al. Mirtazapine versus other antidepressants in the acute-phase treatment of adults with major depression: Systematic review and meta-analysis. J Clin Psychiatry. 2008;69(9):1404-1415.

87. Guelfi JD, Ansseau M, Timmerman L, Kørsgaard S. Mirtazapine versus venlafaxine in hospitalized severely depressed patients with melancholic features. J Clin Psychopharmacol. 2001;21(4): 425-431.
88. Papakostas GI, Homberger CH, Fava M. A meta-analysis of clinical trails comparing mirtazapine with selective serotonin reuptake inhibitors for the treatment of major depressive disorder. J Psychopharmacol. 2008;22(8):843-848.

89. Stahl SM, Pradko JF, Haight BR, Modell JG, Rockett CB, LearnedCoughlin S. A review of the neuropharmacology of bupropion, a dual norepinephrine and dopamine reuptake inhibitor. Prim Care Companion J Clin Psychiatry. 2004;6(4):159-166.

90. Dhillon S, Yang LPH, Curran MP. Bupropion: A review of its use in the managment of major depressive disorder. Drugs. 2008;68(5): 653-689.

91. Jefferson JW, Pradko JF, Muir KT. Bupropion for major depressive disorder: Pharmacokinetic and formulation considerations. Clin Ther. 2005;27(11):1685-1695.

92. Rotzinger S, Bourin M, Akimoto Y, Coutts RT, Baker GB. Metabolism of some "second" and "fourth" generation antidepressants: Iprindole, viloxazine, bupropion, mianserin, maprotilin, trazodone, nefazodone, and venlafaxine. Cell Mol Neurobiol. 1999;19(4): 427-442.

93. Hesse LM, Venkatakrishnan K, Court MH, et al. CYP2B6 mediates the in vitro hydroxylation of bupropion: Potential drug interactions with other antidepressants. Drug Metab Dispos. 200;28(10): 1176-1183.

94. Kirchheiner J, Klein C, Meineke I, et al. Bupropion and 4-OHbupropion pharmacokinetics in relation to genetic polymorphisms in CYP2B6. Pharmacogenetics. 2003;13(10):619-626.

95. Ketter TA, Jenkins JB, Schroeder DH, et al. Carbamazepine but not valproate induces bupropion metabolism. J Clin Psychopharmacol. 1995;15(5):327-333.

96. Hogeland GW, Swindells S, McNabb JC, Kashuba AD, Yee GC, Lindley CM. Lopinavir/ritonavir reduces bupropion plasma concentrations in healthy subjects. Clin Pharmacol Ther. 2007;81(1):69-75.

97. Kennedy SH, McCann SM, Masellis M, et al. Combining bupropion SR with venlafaxine, paroxetine, or fluoxetine: A preliminary report on pharmacokinetic, therapeutic, and sexual dysfunction effects. JClin Psychiatry. 2002;63(3):181-186.

98. McCollum DL, Greene JL, McGuire DK. Severe sinus bradycardia after initiation of bupropion therapy: A probable drug-drug interaction with metoprolol. Cardiovasc Drugs Ther. 2004;18(4):329-330.

99. Stewart JJ, Berkel HJ, Parish RC, et al. Single-dose pharmacokinetics of bupropion in adolescents: Effects of smoking status and gender. J Clin Pharmacol. 2001;41(7):770-778.

100. Hsyu PH, Singh A, Giargiari TD, Dunn JA, Ascher JA, Johnston JA. Pharmacokinetics of bupropion and its metabolites in cigarette smokers versus nonsmokers. J Clin Pharmacol. 1997;37(8): 737-743.

101. Sweet RA, Pollock BG, Kirshner M, Wright B, Altieri LP, DeVane CL. Pharmacokinetics of single- and multiple-dose bupropion in elderly patients with depression. J Clin Pharmacol. 1995;35(9): $876-884$

102. Turpeinen M, Koivuviita N, Tolonen A, et al. Effect of renal impairment on the pharmacokinetics of bupropion and its metabolites. Br J Clin Pharmacol. 2007;64(2):165-173.

103. Reimherr FW, Cunningham LA, Batey SR, Johnston JA, Ascher JA. A multicenter evaluation of the efficacy and safety of 150 and $300 \mathrm{mg} / \mathrm{d}$ sustained-release bupropion tablets versus placebo in depressed outpatients. Clin Ther. 1998;20(3):505-516.

104. Jefferson JW, Rush AJ, Nelson JC, et al. Extended-release bupropion for patients with major depressive disorder presenting with symptoms of reduced energy, pleasure, and interest: Findings from a randomized, double-blind, placebo-controlled study. J Clin Psychiatry. 2006;67(6):865-873.

105. Masco HL, Kiev A, Holloman LC, Batey SR, Johnston JA, Lineberry CG. Safety and efficacy of bupropion and nortriptyline in outpatients with depression. Curr Ther Res. 1994;55(7):851-863. 
106. Mendels J, Amin MM, Chouinard G, et al. A comparative study of bupropion and amitriptyline in depressed outpatients. J Clin Psychiatry. 1983;44(5 Pt 2):118-120.

107. Feighner JP, Gardner EA, Johnston JA, et al. Double-blind comparison of bupropion and fluoxetine in depressed outpatients. J Clin Psychiatry. 1991;52(8):329-335.

108. Coleman CC, King BR, Bolden-Watson C, et al. A placebo-controlled comparison of the effects on sexual functioning of bupropion sustained release and fluoxetine. Clin Ther. 2001;23(7):1040-1058.

109. Weihs KL, Settle E Jr, Batey SR, Houser TL, Donahue RM, Ascher JA. Bupropion sustained release versus paroxetine for the treatment of depression in the elderly. J Clin Psychiatry. 2000;61(3): 196-202.

110. Clayton AH, Croft HA, Horrigan JP, et al. Bupropion extended release compared with escitalopram: Effects on sexual functioning and antidepressant efficacy in two randomized, double-blind, placebo-controlled studies. J Clin Psychiatry. 2006;67(5):736-746.

111. Hewett K, Chrzanowski W, Schmitz M, et al. Eight-week, placebocontrolled, double-blind comparison of the antidepressant efficacy and tolerability of bupropion XR and venlafaxine XR. J Psychopharmacol. 2009;23(5):531-538.

112. Thase ME, Clayton AH, Haight BR, Thompson AH, Modell JG, Johnston JA. A double-blind comparison between bupropion XR and venlafaxine XR: Sexual functioning, antidepressant efficacy, and tolerability. J Clin Psychopharmacol. 2006;26(5): 482-488.

113. Rush AJ, Trivedi MH, Wisniewski SR, et al. Bupropion-SR, sertraline, or venlafaxine-XR after failure of SSRIs for depression. N Engl J Med. 2006;354(12):1231-1242.

114. Trivedi MH, Fava M, Wisniewski SR, et al. Medication augmentation after the failure of SSRIs for depression. $N$ Eng J Med. 2006; 354(12):1243-1252.

115. Roseboom PH, Kalin NH. Neuropharmacology of venlafaxine. Depress Anxiety. 2000;12 Suppl 1:S20-S29.

116. Troy SM, Parker VD, Fruncillo RJ, Chiang ST. The pharmacokinetics of venlafaxine when given in twice-daily regimen. J Clin Pharmacol. 1995;35(4):404-409.

117. Troy SM, Dilea C, Martin PT, Leister CA, Fruncillo RJ, Chiang ST. Pharmacokinetics of once-daily venlafaxine extended release in healthy volunteers. Curr Ther Res. 1997;56(8):504-514.

118. Ereshefsky L, Dugan D. Review of the pharmacokinetics, pharmacogenetics, and drug interaction potential of antidepressants: Focus on venlafaxine. Depress Anxiety. 2000;12 Suppl 1:S30-S44.

119. Ilett KF, Kristensen JH, Hackett P, Paech M, Kohan R, Rampono J. Distribution of venlafaxine and its O-desmethyl metabolite in human milk and their effects in breastfed infants. Br J Clin Pharmacol. 2002;53(1):17-22.

120. Otton SV, Ball SE, Cheung SW, Inaba T, Rudolph RL, Sellers EM. Venlafaxine oxidation in vitro is catalysed by CYP2D6. Br J Clin Pharmacol. 1996;41(2):149-156.

121. Fogelman SM, Schmider J, Venkatakrishnan K, et al. $O$ - and $N$ - demethylation of venlafaxine in vitro by human liver microsomes and by microsomes from cDNA-transfected cells: Effect of metabolic inhibitors and SSRI antidepressants. Neuropsychopharmacology. 1999;20(5):480-490.

122. Preskorn S, Patroneva A, Silman H, et al. Comparation of the pharmacokinetics of venlafaxine extended release and desvenlafaxine in extensive and poor cytochrome P450 2D6 metabolizers. $J$ Clin Psychopharmacol. 2009;29(1):39-43.

123. Preskorn SH, Nichols AI, Paul J, Patraneva AL, Helzner EC, Guico-Pabia CJ. Effect of desvenlafaxine on the cytochrome P450 2D6 enzyme system. J Psychiatr Pract. 2008;14(6): 368-378.

124. Albers LJ, Reist C, Vu RL, et al. Effect of venlafaxine on imipramine metabolism. Psychiatry Res. 2000;96(3):235-243.
125. Amchin J, Zarycranski W, Taylor KP, Albano D, Klockowski PM. Effect of venlafaxine on the pharmacokinetics of risperidone. J Clin Pharmacol. 1999;39(3):297-309.

126. Lessard E, Yessine MA, Hamelien BA, et al. Diphenhydramine alters the disposition of venlafaxine through inhibition of CYP2D6 activity in humans. J Clin Psychopharmacol. 2001;21(2):175-184.

127. Troy SM, Schultz RW, Parker VD, Chiang ST, Blum RA. The effect of renal diseaase on the disposition of venlafaxine. Clin Pharmacol Ther. 1994;56(1):14-21.

128. Howell SR, Husbands GEM, Scatina JA, Sisenwine SF. Metabolic disposition of 14C-venlafaxine in mouse, rat, dog, rhesus monkey and man. Xenobiotica. 1993;23(4):349-59.

129. Klamerus KJ, Parker VD, Rudolph RL, Derivan AT, Chiang ST. Effects of age and gender on venlafaxine pharmacokinetics. Pharmacotherapy. 1996;16(5):915-23.

130. Thase ME. Efficacy and tolerability of once-daily venlafaxine extended release (XR) in outpatients with major depression. The Venlafaxine XR 209 Study Group. J Clin Psychiatry. 1997;58(9): 393-398

131. Bauer M, Tharmanathan P, Volz HP, Moeller HJ, Freemantle N. The effect of venlafaxine compared with other antidepressants and placebo in the treatment of major depression. Eur Arch Psychiatry Clin Neurosci. 2009;259(3):172-185.

132. Sir A, D'Souza RF, Uguz S, et al. Randomized trial of sertraline versus venlafaxine XR in major depression: Efficacy and discontinuation symptoms. J Clin Psychiatry. 2005;66(10):1312-1320.

133. Thase M, Entsuah A, Rudolph R. Remission rates during treatment with venlafaxine or selective serotonine reuptake inhibitors. Br J Psychiatry. 2001;178(3):234-241.

134. Thase ME, Entsuah R, Ahmed S, Sloan DM, Nemeroff CB. Metaanalysis of randomized controlled trials comparing venlafaxine and SSRIs: The evidence revisited. Presented at the 2005 annual meeting of the American Psychiatric Association, Atlanta, Georgia, May 21-26, 2005

135. Anderson IM. Meta-analytical studies of new antidepressants. Br Med Bull. 2001;57(1):161-178.

136. Hansen RA, Gartlehner G, Lohr KN, Gaynes BN, Carey TS. Efficacy and safety of second-generation antidepressants in the treatment of major depressive disorder. Ann Intern Med. 2005;143(6): 415-426.

137. Lenox-Smith A, Greenstreet L, Burslem K, Knight C. Cost effectivness of venlafaxine compared with generic fluoxetine or generic amitriptyline in major depressive disorder in the UK. Clin Drug Investig. 2009;29(3):173-184

138. Liebowitz MR, Manley AL, Padmanabhan SK, Ganguly R, Tummala R, Tourian KA. Efficacy, safety, and tolerability of desvenlafaxine $50 \mathrm{mg} /$ day and $100 \mathrm{mg} /$ day in outpatients with major depressive disorder. Curr Med Res Opin. 2008;24(7):1877-1890.

139. Feighner JP. The role of venlafaxine in rational antidepressant therapy. J Clin Psychiatry. 1994;55 (Suppl A):62-68.

140. Haddad PM. Antidepressant discontinuation syndromes. Drug Saf. 2001;24(3):183-197.

141. Buckley NA, McManus PR. Fatal toxicity of serotoninergic and other antidepressant drugs: Analysis of United Kingdom mortality data BMJ. 2002;325(7376):1332-1333.

142. Thase ME, Shelton RC, Khan A. Treatment with venlafaxine extended-release after SSRI nonresponse or intolerance: A randomized comparison of standard- and higher-dosing strategies. J Clin Psychopharmacol. 2006;26(3):250-258.

143. Pae CU. Desvenlafaxine: A new antidepressant or just another one. Expert Opin Pharmacother. 2009;10(5):875-887.

144. Claytone AH, Kornstein SG, Rosas G, Guico-Pabia, Tourian KA. An integrated analysis of the safety and tolerability of desvenlafaxine compared with placebo in the treatment of major depressive disorder. CNS Spectr. 2009;14(4):183-195. 
145. Guelfi JD, White C, Hackett D, Guichoux JY, Magni G. Effectiveness of venlafaxine in patients hospitalized for major depression and melancholia. J Clin Psychiatry. 1995;56(10):450-458.

146. Bymaster FP, Dreshfield-Ahmad LJ, Threlkeld PG, et al. Comparative affinity of duloxetine and venlafaxine for serotonin and norepinephrine transporters in vitro and in vivo, human serotonin receptor subtypes, and other neuronal receptors. Neuropsychopharmacology. 2001; 25(6):871-880.

147. Zhao RK, Cheng G, Tang J, Song J, Peng WX. Pharmacokinetics of duloxetine hydrocloride enteric-coated tablets in healthy Chinese volunteers: A randomized, open-label, single- and multiple-dose study. Clin Ther. 2009;31(5):1022-1036.

148. Skinner MH, Skerjanec A, Seger M, Hewitt R. The effect of food and bedtime administration on duloxetine pharmacokinetics. Clin Pharmacol Ther. 2000;67(2):129. Abstract.

149. Sharma A, Goldberg MJ, Cerimele BJ. Pharmacokinetics and safety of duloxetine, a dual-serotonin and norepinephrine reuptake inhibitor. J Clin Pharmacol. 2000;40(2): $161-167$.

150. Frampton JE, Plosker GL. Duloxetine: A review of its use in the treatment of major depressive disorder. CNS Drugs. 2007;21(7): 581-609.

151. Lantz RJ, Gillespie TA, Rash TJ, et al. Metabolism, exretion, and pharmacokinetics of duloxetine in healthy human subjects. Drug Metab Dispos. 2003;31(9).1142-1150.

152. Lobo ED, Bergstrom RF, Reddy $\mathrm{S}$, et al. In vitro and in vivo evaluations of cytochrome P450 1A2 interactions with duloxetine. Clin Pharmacokinet. 2008;47(3):191-202.

153. Hunziker ME, Suehs BT, Bettinger TL, Crismon ML. Duloxetine hydrochloride: A new dual-acting medication for the treatment of major depressive disorder. Clin Ther. 2005;27(8): 1126-1143.

154. Skinner MH, Kuan HY, Pan A, et al. Duloxetine is both an inhibitor and a substrate of cytochrome P450 2D6 in healthy volunteers. Clin Pharmacol Ther. 2003;73(3):170-177.

155. Lobo ED, Quinlan T, O'Brien L, Pat Knadler M, Heathman M. Population pharmacokinetics of orally administered duloxetine in patients. Clin Pharmacokinet. 2009;48(3):189-197.

156. Suri A, Reddy S, Gonzales DR, Knadler MP, Skinner M. Duloxetine pharmacokinetics in cirrhotics compared with healthy subjects. Int $J$ Clin Pharmacol Ther. 2005;43(2): 78-84.

157. Brannan SK, Mallinckrodt CH, Brown EB, Wohlreich MM, Watkin JJG, Schatzberg AF. Duloxetine $60 \mathrm{mg}$ once daily in the treatment of painful physical symptoms in patients with major depressive disorder. J Psychiatr Res. 2005;39(1): 43-53.

158. Spielmans GI. Duloxetine does not relieve painful physical symptoms in depression: A meta-analysis. Psychother Psychosom. 2008;77(1):12-16.

159. Thase ME, Pritchett YL, Ossanna MJ, Swindle RW, Xu J, Detke MJ. Efficacy of duloxetine and selective serotonin reuptake inhibitors: Comparisons as assessed by remission rates in patients with major depressive disorder. J Clin Psychopharmacol. 2007;27(6): 672-676.

160. Perahia DG, Pritchett YL, Kajdasz DK, et al. A randomized, double blind comparison of duloxetine and venlafaxine in the treatment of patients with major depressive disorder. $J$ Psychiatr Res. 2008;42(1):22-34.

161. Gupta S, Nihalani N, Masand P. Duloxetine: Review of its pharmacology, and therapeutic use in depression and other psychiatric disorders. Ann Clin Psychiatry. 2007;19(2):125-132.

162. Wade A, Gembert K, Florea I. A comparative study of the efficacy of acute and continuation treatment with escitalopram versus duloxetine in patients with major depressive disorder. Curr Med Res Opin. 2007;23(7):1605-1614.
163. Nierenberg AA, Greist JH, Mallinckrodt CH, et al. Duloxetine versus escitalopram and placebo in the treatment of patients with major depressive disorder: Onset of antidepressant action, a non-inferiority study. Curr Med Res Opin. 2007;23(2): $401-416$.

164. Mallinckrodt CH, Prakash A, Andorn AC, Watkin JG, Wohlreich MM. Duloxetine for the treatment of major depressive disorder: A closer look at efficacy and safety data across the approved dose range. J Psychiatr Res. 2006;40(4):337-348.

165. Wise TN, Perahia DG, Pangallo BA, Losin WG, Wiltse CG. Effects of the antidepressants duloxetine on body weight: Analysis of 10 clinical studies. Prim Care Companion J Clin Psychiatry. 2006;8(5):269-278.

166. Thase ME, Tran PV, Wiltse C, Pangallo BA, Mallinckrodt C, Detke MJ. Cardiovascular profile of duloxetine, a dual reuptake inhibitor of serotonin and norepinephrine. J Clin Psychopharmacol. 2005;25(2): $132-140$.

167. Delgado PL, Brannan SK, Mallinckrodt CH, et al. Sexual functioning assessed in 4 double-blind placebo- and paroxetine- controlled trials of duloxetine for major depressive disorder. J Clin Psychiatry. 2005; 66(6):686-692.

168. Nelson JC, Lu Pritchett Y, Martynov O, Yu JY, Mallinckrodt $\mathrm{CH}$, Detke MJ. The safety and tolerability of duloxetine compared with paroxetine and placebo: A pooled analysis of 4 clinical trials. Prim Care Companion J Clin Psychiatry. 2006;8(4): 212-219.

169. Spencer CM, Wilde MI. Milnacipran: A review of its use in depression. Drugs. 1998;56(3):405-427.

170. Vaishnavi SN, Nemeroff CB, Plott SJ, Rao SG, Kranzler J, Owens MJ. Milnacipran: A comparative analysis of human monoamine uptake and transporter binding affinity. Biol Psychiatry. 2004; 55(3):320-322.

171. Hindmarch I, Rigney U, Stanley N, Briley M. Pharmacodynamics of milnacipran in young and elderly volunteers. Br J Clin Pharmacol. 2000;49(2):118-125.

172. Cada DJ, Levien TL, Baker DE. Milnacipran. Hosp Pharm. 2009;44(7): 604-615.

173. Puozzo C, Lens S, Reh C, et al. Lack of interactions of milnacipran with the cytochrome P450 isoenzymes frequently involved in the metabolism of antidepressants. Clin Pharmacokinet. 2005;44(9):977-988.

174. Puozzo C, Leonard BE. Pharmacokinetics of milnacipran in comparison with other antidepressants. Int Clin Psychopharmacol. 1996; 11 Suppl 4:S15-S27.

175. Puozzo C, Hermann P, Chassard D. Lack of pharmacokinetic interaction when switching from fluoxetine to milnacipran. Int Clin Psychopharmacol. 2006;21(3):153-158.

176. LecrubierY, PletanY, Solles A, Tournoux A, Magne V. Clinical efficacy of milnacipran: Placebo-controlled trials. Int Clin Psychopharmacol. 1996; 11 Suppl 4:S29-S33.

177. Macher JP, Sichel JP, Serre C, Von Frenckell R, Huck JC, Demarez JP. Double-blind placebo-controlled study of milnacipran in hospitalized patients with major depressive disorders. Neuropsychobiology. 1989;22(2):77-82.

178. Papakostas GI, Fava M. A meta-analysis of clinical trials comparing milnacipran, a serotonin-norepinephrine reuptake inhibitor for the treatment of major depressive disorder. Eur Neuropsychopharmacol. 2007;17(1):32-36.

179. Nakagawa A, Watanabe N, Omori IM, et al. Efficacy and tolerability of milnacipran in the treatment of major depression in comparison with other antidepressants: A systemic review and meta-analysis. CNS Drugs. 2008;22(7):587-602.

180. Wong EHF, Sonders MS, Amara SG, et al. Reboxetine: A pharmacologically potent, selective, and specific norepinephrine reuptake inhibitor. Biol Psychiatry. 2000;47(9): 818-829. 
181. Fleishaker JC. Clinical pharmacokinetics of reboxetine, a selective norepinephrine reuptake inhibitor for the treatment of patients with depression. Clin Pharmacokinet. 2000;39(6): 413-427.

182. Edwards DM, Pellizzioni C, Breuel HP, et al. Pharmacokinetics of reboxetine in healthy volunteers. Single oral doses, linearity and plasma protein binding. Biopharm Drug Dispos. 1995; 16(6):443-460.

183. Fleishaker JC, Mucci M, Pellizzioni C, Poggesi I. Absolute bioavailability of reboxetine enantiomers and effects of gender on pharmacokinetics. Biopharm Drug Dispos. 1999;20(1): 53-57.

184. Pellizzioni C, Benedetti Strolin M, Poggesi I, Frigerio E, Toon S, Langley SJ. Pharmacokinetics of reboxetine in healthy volunteers: Relative bioavailability and food effect. Pharmacol Res. 1995;31 Suppl 1:S41.

185. Wienkers LC, Allievi C, Hauer MJ, Wynalda MA. Cytochrome P450-mediated metabolism of the individual enantiomers of the antidepressant agent reboxetine in human liver microsomes. Drug Metab Dispos. 1999;27(11):1334-1340.

186. Hendershot PE, Fleishaker JC, Lin KM, Nuccio ID, Poland RE. Pharmacokinetics of reboxetine in healthy volunteers with different ethnic descents. Psychopharmacology. 2001;155(2): $148-153$.

187. Poggesi I, Pellizzoni C, Fleishaker JC. Pharmacokinetics of reboxetine in elderly patients with depressive disorders. Int J Clin Pharmacol Ther. 2000;38(5):254-259.

188. Bergmann JF, Laneury JP, Duchene P, Fleishaker JC, Houin G, Ségrestaa JM. Pharmacokinetics of reboxetine in healthy, elderly volunteers. Eur J Drug Metab Pharmacokinet. 2000;25(3-4):195-198.

189. Coulomb F, Ducret F, Laneury JP, et al. Pharmacokinetics of singledose reboxetine in volunteers with renal insufficiency. J Clin Pharmacol. 2000;40(5):482-487.

190. Tran A, Laneury JP, Duchêne P, et al. Pharmacokinetics of reboxetine in volunteers with hepatic impairment. Clin Drug Invest. 2000;19(6):473-477.

191. Montgomery S, Ferguson JM, Schwartz GE. The antidepressant efficacy of reboxetine in patients with severe depression. J Clin Psychopharmacol. 2003;23(1):45-50.

192. Versiani M, Mehilane L, Gaszner P, Arnaud-Castiglioni R. Reboxetine, a unique selective NRI, prevents relapse and recurrence in long-term treatment of major depressive disorder. J Clin Psychiatry. 1999; 60(6):400-406

193. Berzewski H, Van Moffaert M, Gagiano CA. Efficacy and tolerability of reboxetine compared with imipramine in a double-blind study in patients suffering from major depressive offsodes. Eur Neuropsychopharmacol. 1997;7 Suppl 1:S37-S47.

194. Katona C, Bercoff E, Chiu E, Tack P, Versiani M, Woelk H. Reboxetine versus imipramine in the treatment of elderly patients with depressive disorders: A double-blind randomized trial. JAffect Disord. 1999;55(2-3):203-213.

195. Montgomery SA. Chairman's overview. The place of reboxetine in antidepressant therapy. J Clin Psychiatry. 1998;59 Suppl 14 S26-S29.

196. Massana J, Moller HJ, Burrows SG, Montenegro RM. Reboxetine: A double-blind comparison with fluoxetine in major depressive disorder. Int Clin Psychopharmacol. 1999;14(2): $73-80$.

197. Andreoli V, Caillard V, Deo RS, Rybakowski JK, Versiani M. Reboxetine, a new noradrenaline selective antidepressant, is at least as effective as fluoxetine in treatment of depression. J Clin Psychopharmacol. 2002;22(4):393-399.

198. Kasper S, Hamon M. Beyond the monoaminergic hypothesis: Agomelatine, a new antidepressant with an innovative mechanism of action. World J Biol Psychiatry. 2009;10(2):117-126.
199. Zupancic M, Guilleminault C. Agomelatine: A preliminary review of a new antidepressant. CNS Drugs. 2006;20(12): 981-992.

200. Millan MJ, Gobert A, Lejeune F, et al. The novel melatonin agonist agomelatine (S20098) is an antagonist at 5-hydroxytryptamine (2C) receptors, blockade of which enhances the activity of frontocortical dopaminergic and adrenergic pathways. J Pharmacol Exp Ther. 2003;306(3):954-964.

201. Servier. Valdoxan. Summary of product characteristics. Available from: http://www.servier.co.uk/pdfs/Valdoxan_SPC.pdf . Accessed on 2010 May 5 .

202. Kennedy SH, Emsley R. Placebo-controlled trial of agomelatine in the treatment of major depressive disorder. Eur Neuropsychopharmacol. 2006;16(2):93-100.

203. Loo H, Hale A, D'haenen H. Determination of the dose of agomelatine, a melatoninergic agonist and selective 5-HT2C antagonist, in the treatment of major depressive disorder: A placebocontrolled dose range study. Int Clin Psychopharmacol. 2002;17(5): 239-247

204. Montgomery SA, Kasper S. Severe depression and antidepressants: Focus on a pooled analysis of placebo-controlled studies on agomelatine. Int Clin Psychopharmacol. 2007;22(5): 283-291.

205. Kennedy SH. Sexual function in remitted depressed patients following agomelatine and venlafaxine XR treatment. Eur Neuropsychopharmacol. 2005;15 Suppl 3:Abstr S440.

206. Guilleminault C. Efficacy of agomelatine versus venlafaxine on subjective sleep of patients with major depressive disorder. Eur Neuropsychopharmacol. 2005;15 Suppl 3:S419-S420. Abstract.

207. Mongomery SA, Kennedy SH, Burrows GD, Lejoyeux M, Hindmarch I. Absence of discontinuation symptoms with agomelatine and occurrence of discontinuation symptoms with paroxetine: A randomized, double-blind, placebo-controlled discontinuation study. Int Clin Psychopharmacol. 2004;19(5): 271-280.

208. Weber J, Lyseng-Williamson KA, Scott LJ. Aripiprazole: In major depressive disorder. CNS Drugs. 2008;22(10):807-813.

209. Berman RM, Marcus RN, Swanink R. The efficacy and safety of aripiprazole as adjunctive therapy in major depressive disorder: A multicenter, randomized, double-blind, placebo-controlled study. J Clin Psychiatry. 2007;68(6):843-853.

210. Marcus RN, McQuade RD, Carson WH, et al. The efficacy and safety of aripiprazole as adjunctive therapy in major depressive disorder: A second multicenter, randomized, double-blind, placebo-controlled study. J Clin Psychopharmacol. 2008;28(2): 156-165.

211. Carroll BJ. Aripiprazole in refractory depression? J Clin Psychopharmacol. 2009;29(1):90-91.

212. Tsai AC. Unclear clinical significance of findings in adjunctive aripiprazole for major depressive disorder. Comments on article by Marcus et al. J Clin Psychopharmacol. 2009;29(1): 91-92.

213. Dawson LA, Watson JM. Vilazodone: A 5-HT1A receptor agonist/ serotonin transporter inhibitor for the treatment of affective disorders. CNS Neurosci Ther. 2009;15(2):107-117.

214. Rickels K, Athanasiou M, Robinson DS, Gibertini M, Whalen H, Reed CR. Evidence for efficacy and tolerability of vilazodone in the treatment of major depressive disorder: A randomized, doubleblind, placebo-controlled trial. J Clin Psychiatry. 2009;70(3): 326-333.

215. Millan MJ. Dual- and triple-acting agents for treating core and comorbid symptoms of major depression: Novel concepts, new drugs. Neurotherapeutics. 2009;6(1):53-77.

216. Sen S, Sanacora G. Major depression: Emerging therapeutics. Mt Sinai J Med. 2008;75(3):204-225. 
217. NeuroSearch announces the results of Phase II proof of concept studies with NS2359 in depression. Available from: https://newsclient. omxgroup.com/cdsPublic/viewDisclosure.action?disclosureId=3130 18\&messageId=372903. Accessed on 2010 May 5.

218. Andrés JI, Alcazar J, Alonso JM, et al. Tricyclic isoxazolines: Identification of R226161 as a new antidepressant that combines potent serotonin reuptake inhibition and $\alpha_{2}$-adrenoceptor antagonism. Bioorg Med Chem. 2007;15(11):3649-3660.

219. Gobert A, Cussac D, Lejeune F, et al. The novel antidepressant, S35966, is a mixed serotonin and noradrenaline reuptake inhibitor and an antagonist at $\alpha_{2}$-adrenoceptors. Eur Neuropsychopharmacol. 2002;12(Suppl 3):S248.
220. Demyttenaere K. Compliance and acceptance in antidepressant treatment. Int J Psych Clin Pract. 2001;5(Suppl 1):S29-S35.

221. Sawada N, Uchida H, Suzuki T, et al. Persistance and compliance to antidepressant treatment in patients with depression: A chart review. BMC Psychiatry. 2009;9:38.

222. Roose SP. Compliance: The impact of adverse events and tolerability on the physician's treatment decisions. Eur Neuropsychopharm. 2003;13(Suppl 3):S85-S92.

223. Haslam C, Brown S, Atkinson S, Haslam R. Patients' experiences of medication for anxiety and depression: Effects on working life. Family Practice. 2004;21(2):204-212.

\section{Publish your work in this journal}

Neuropsychiatric Disease and Treatment is an international, peerreviewed journal of clinical therapeutics and pharmacology focusing on concise rapid reporting of clinical or pre-clinical studies on a range of neuropsychiatric and neurological disorders. This journal is indexed on PubMed Central, the 'PsycINFO' database and CAS, and is the official journal of The International Neuropsychiatric Association (INA). The manuscript management system is completely online and includes a very quick and fair peer-review system, which is all easy to use. Visit http://www.dovepress.com/testimonials.php to read real quotes from published authors.

Submit your manuscript here: http://www.dovepress.com/neuropsychiatric-disease-and-treatment-journal 